\title{
Seafloor change detection using multibeam echosounder backscatter: case study on the Belgian part of the North Sea
}

\author{
Giacomo Montereale-Gavazzi ${ }^{1,2} \cdot$ Marc Roche $^{3} \cdot$ Xavier Lurton $^{4} \cdot$ Koen Degrendele $^{3} \cdot$ \\ Nathan Terseleer ${ }^{1} \cdot$ Vera Van Lancker ${ }^{1,2}$
}

Received: 29 December 2016 / Accepted: 26 May 2017 / Published online: 31 May 2017

(c) The Author(s) 2017. This article is an open access publication

\begin{abstract}
To characterize seafloor substrate type, seabed mapping and particularly multibeam echosounding are increasingly used. Yet, the utilisation of repetitive MBESborne backscatter surveys to monitor the environmental status of the seafloor remains limited. Often methodological frameworks are missing, and should comprise of a suite of change detection procedures, similarly to those developed in the terrestrial sciences. In this study, pre-, ensemble and post-classification approaches were tested on an eight $\mathrm{km}^{2}$ study site within a Habitat Directive Area in the Belgian part of the North Sea. In this area, gravel beds with epifaunal assemblages were observed. Flourishing of the fauna is constrained by overtopping with sand or increased turbidity levels, which could result from anthropogenic activities. Monitoring of the gravel to sand ratio was hence put forward as an indicator of good environmental status. Seven acoustic surveys were undertaken from 2004 to 2015. The methods allowed quantifying temporal trends and patterns of change of the main substrate classes identified in the study area; namely fine to medium homogenous sand, medium sand with bioclastic detritus and medium to coarse sand with gravel. Results indicated that by considering the
\end{abstract}

Giacomo Montereale-Gavazzi

gmonterealegavazzi@naturalsciences.be

1 Operational Directorate Natural Environment, Royal Belgian Institute of Natural Sciences, Gulledelle 100, 1200 Brussels, Belgium

2 Renard Centre of Marine Geology Department of Geology, Ghent University, Krijgslaan 281, 9000 Ghent, Belgium

3 Federal Public Service Economy, Continental Shelf Service, Boulevard du Roi Albert II 16, 1000 Brussels, Belgium

4 Underwater Acoustics Laboratory, Ifremer, IMN/NSE/ASTI, CS 10070, 29280 Plouzané, France entire study area and the entire time series, the gravel to sand ratio fluctuated, but was overall stable. Nonetheless, when only the biodiversity hotspots were considered, net losses and a gradual trend, indicative of potential smothering, was captured by ensemble and post-classification approaches respectively. Additionally, a two-dimensional morphological analysis, based on the bathymetric data, suggested a loss of profile complexity from 2004 to 2015 . Causal relationships with natural and anthropogenic stressors are yet to be established. The methodologies presented and discussed are repeatable and can be applied to broadscale geographical extents given that broad-scale time series datasets become available.

Keywords Multibeam - Seafloor backscatter - Change detection · Seafloor integrity · Marine Strategy Framework Directive $\cdot$ Reference calibration area

\section{Introduction}

Human pressures to the marine biome have reached unprecedented extents. Today, globally up to $41 \%$ of marine habitats are directly impacted by a multitude of anthropogenic stressors (Halpern et al. 2008). Changes in seafloor substrate composition and spatial configuration may occur as a result of such anthropogenic pressure, but also of natural variability driven by varying hydrometeorological conditions (van Denderen et al. 2015). Our ability to monitor the spatio-temporal dynamics of the seafloor and, ultimately, to relate the observed patterns to driving processes is central to our understanding of marine ecosystems and to the tutelage of the ecosystem services we depend on. This is also recognized in the European Marine Strategy Framework Directive 
(MSFD-EC 2008-56-EC) in which the seafloor is the backbone of several indicators of 'Good Environmental Status'. For this purpose, seabed mapping, and particularly multibeam echosounding are increasingly used.

High-frequency multibeam echosounders (MBES) are considered as the state-of-the-art sonar instruments and are employed by commercial, governmental (i.e. hydrographic services), industry (e.g. oil and gas exploration and exploitation), and research institutions. This is due to the MBES ability to co-register high-density echo time, geometrical features and intensity over large seabed swaths, hence providing depth and intensity data (Kenny et al. 2003). While up until now the bathymetry has been the main focus of hydrographic surveys and mapping programs (i.e. following International Hydrographic Organisation standards of acquisition and accuracy of depth measurements; Wells and Monahan 2002), seafloor reflectivity (backscattered intensity from the seafloor) has only recently attracted interest from a scientific perspective due to its ability to map the water-sediment-interface constituency (Lurton and Lamarche 2015). Mapping this interface over vast areas allows extending information from isolated point locations (in-situ measurements such as grab samples and video observations) to the spatial extent of a digital surface. Moreover, if time series of acoustic data are acquired, it allows the application of change detection methods as developed in the terrestrial sciences with satellite data (e.g. Foody 2002; Pontius et al. 2004; Hussain et al. 2013). This raises the possibility to measure how much the attributes of a particular area have changed between two or more periods.

Despite the increasing interest of using MBES backscatter, standards of seabed backscatter acquisition and processing are still under development. A set of guidelines and recommendations was developed by the Backscatter Working Group (or BSWG; see http://geohab.org/ bswg) mandated by the Geological and Biological Marine Habitat Mapping scientific committee (GEOHAB). Reaching standardisation of MBES data acquisition and processing procedures is challenging due to the number of manufacturers, multibeam models and dedicated processing platforms, each implementing their own processing algorithms and proprietary software features.

This paper addresses the application of change detection methods to capture seafloor substrate changes over a period of 10 years based on a time series of seven datasets of MBES depth and backscatter data (2004-2015). It relates to assessing good environmental status of gravel beds in the Belgian part of the North Sea (BPNS) for which the Belgian State specified two indicators on seafloor integrity (MSFD descriptor 6) and for which multibeam technology was put forward as monitoring tool (Belgian State 2012):
1. The areal extent and distribution of the European Nature Information System (EUNIS) level 3 Habitats (sandy mud to mud; muddy sand to sand and coarse sediments), as well as of the gravel beds, remain within the margin of uncertainty of the sediment distribution with reference to the Initial Assessment.

2. Specifically related to the gravel beds it is furthermore specified that the ratio of the hard (gravel) substrate surface area to the soft (sand) substrate surface area must not show a negative trend.

The case study is located within a sandbank system in a Habitat Directive Area of the BPNS. While of high ecological relevance, this area is intensively fished and marine aggregate extraction started in 2012 near its northern limit. In this paper a methodological framework is presented to assess progress of good environmental status based on multibeam backscatter data. Whilst developed at a local scale, the change detection methodology is promising to be applied on a more regional North Sea level.

\section{Study area}

The study site is approximately $8 \mathrm{~km}^{2}$ and is located in the proximity of the Western Border of the BPNS, more specifically in the Vlaamse Banken Habitat Directive Area (enacted as of 16th October 2012, EC 92/43/EEC; Fig. 1, grey-shaded polygon). It is located in the southern part of a complex sandbank-dune system named the Hinder Banks. Depths range from -8 to $-30 \mathrm{~m}$ lowest astronomical tide (LAT). Fine to medium sands dominate the sandbank portion of this environment where large and very-large dunes (ranging from 4 to $>10 \mathrm{~m}$ height) are present (sensu Ashley 1990). The western flank of the main sandbank body forms a transitional area between the bank sandy environment and the adjacent gully. In the latter, medium to coarse sand as well as gravel occur. Gravel provides small-scale structural complexity for ecological successional phases to occur (e.g. deposition of current advected larvae; Houziaux et al. 2007). Seabed maps indicate that the system is very poorly enriched by silt (0-1\% silt-clay content; Verfaillie et al. 2006). A series of steep barchanoid dunes is present in the transitional area, with considerable amounts of gravel in the troughs (Van Lancker 2017). Diverse assemblages of sessile and vagile epifauna and benthic fish were observed here in pioneering and more recent studies (Houziaux et al. 2011, and references therein). Hereafter, these are called gravel refugia, since in the majority of the gully epifaunal growth on gravel beds is absent because of severe bottom-trawling occurring since the late 1800s. In gravel areas, these are known to routinely remobilise the gravel clasts (Jones 1992). 

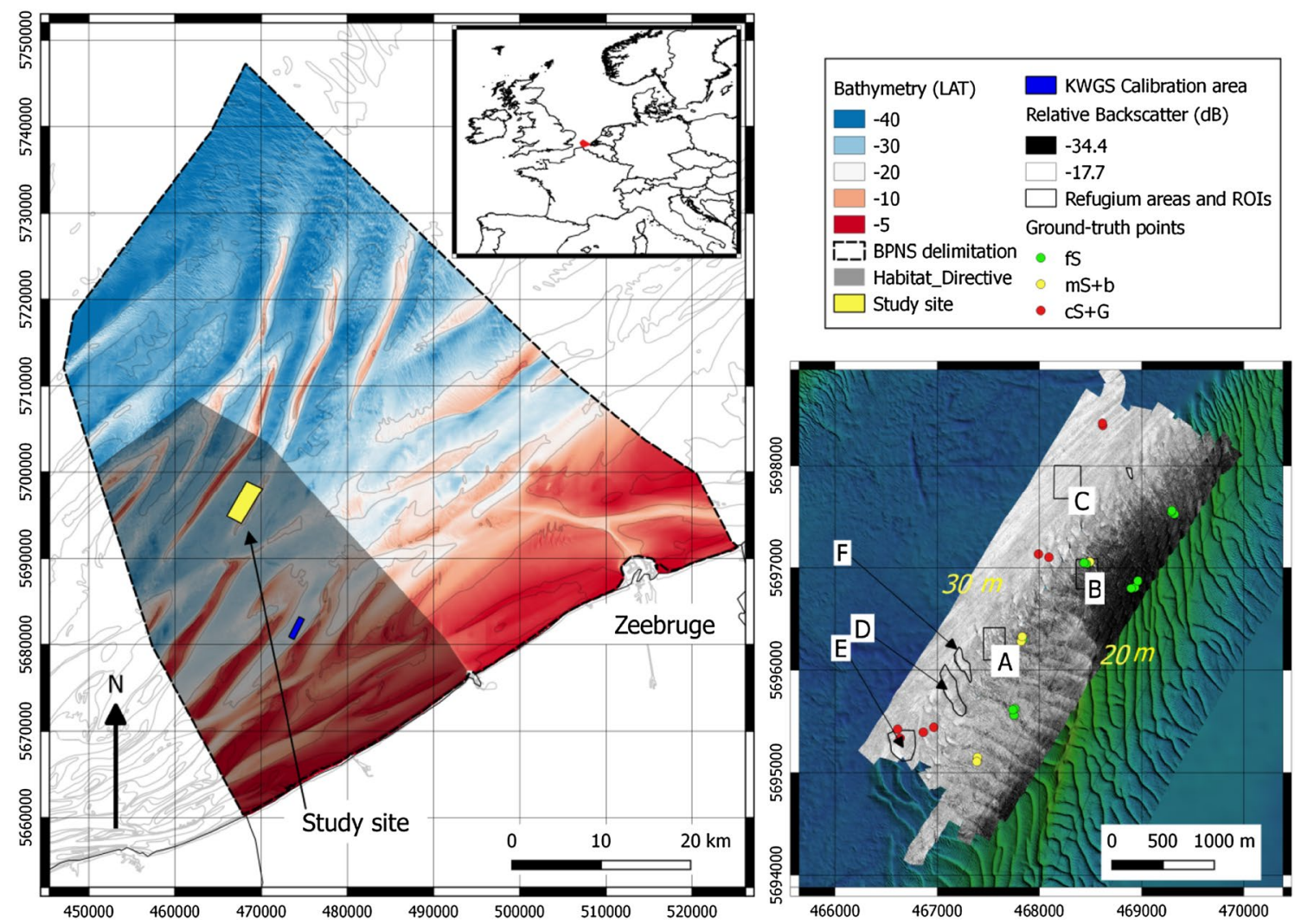

Fig. 1 Left Belgian Part of the North Sea (BPNS). Right backscatter (dB) map of the study area with black outline polygons indicating biodiversity rich areas selected as case studies to monitor seafloor integrity

Since 2012, a new anthropogenic stressor was introduced in the area, related to sand extraction occurring $2.5 \mathrm{~km} \mathrm{NE}$ of the Habitat Directive Area. Depending on timing, frequency and amount of extraction and hydrodynamic settings, resuspension of sediment plumes could represent a source of smothering leading to loss of surficial complexity and burial of epifaunal colonies (Thrush and Dayton 2002; Van Lancker et al. 2010; Spearman 2015). To assess environmental impacts, a monitoring programme was setup combining multibeam recordings with seabed sampling, visual observations and water column measurements as well as hydrodynamic and sediment transport modelling (Van Lancker et al. 2016). Sediment plumes arising from the marine aggregate extraction activities, and their deposition, were depicted in acoustic imagery (Van Lancker and Baeye 2015), and numerical modelling results showed that their deposits reach the gravel beds in the Habitat Directive Area up to the study site (Van Lancker et al. 2016). The cumulative volume of marine aggregates extracted throughout the duration of the data time series is shown in Fig. 2: larger quantities were extracted from 2012 onwards $\left(\sim 800,000 \mathrm{~m}^{3}\right)$ to reach a maximum of $\sim 2.4 \times 10^{6} \mathrm{~m}^{3}$ in 2014.

\section{Methods}

The "Methods" presents the acoustic and ground-truth data acquisition and processing, comprising a two-dimensional characterization of the spatio-temporal morphological evolution of the seafloor using the bathymetry data and a change detection analysis carried out on the backscatter time series. The steps of the analysis preceding the change detection include the application of supervised and unsupervised classification algorithms and their quantitative comparison. Finally, the change detection using backscatter data is carried out by using both classified (thematic/labelled) and unclassified (relative $\mathrm{dB}$ values/unlabelled) backscatter mosaics, as well as applying ensemble approaches.

\section{Data acquisition and processing}

\section{Acquisition}

The MBES data were acquired by Ghent University in 2004, and later by the Operational Directorate of Natural Environment of the Royal Belgian Institute of Natural 


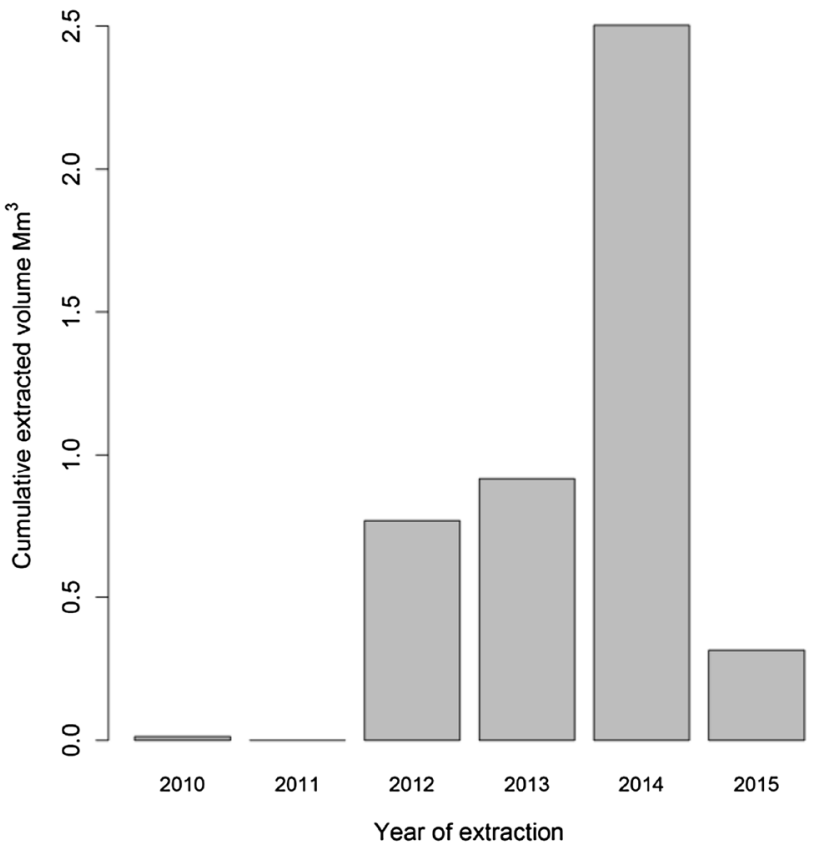

Fig. 2 Extracted marine aggregate volume in $\mathrm{Mm}^{3}$ from Extraction Zone $4(2.5 \mathrm{~km}$ away from the designated area). See Mathys et al. (2011), Van Lancker et al. (2016) for a detailed description on the marine aggregate extraction in this particular area. Effective extraction began in 2012. Data on extraction volumes were provided by the Belgian Federal Public Service Economy, Continental Shelf

Sciences as part of a sand- and gravel-extraction monitoring programme and MSFD-oriented monitoring campaigns (Van Lancker et al. 2016). Of the eight acoustic surveys undertaken between 2004 and 2015, seven were kept for this investigation. Surveys exhibiting a significant amount of navigation artefacts (mostly due to failure in vessel-motion related compensation during rough-sea conditions), were considered unsuitable for the analysis and were discarded. The first survey used a 100-kHz Kongsberg EM1002S, and the remaining six surveys operated a 300kHz Kongsberg EM3002D (Dual-head system). Both systems were installed on Belgian oceanographic vessel R/V Belgica.

The hydrographic quality of the EM3002D dataset is consistent with the IHO S44 Special Order, whereas with the former EM1002S only the Order 1A (Wells and Monahan 2002) was attained. Under these standards, the total vertical uncertainty with $\pm 95 \%$ confidence levels of the depth measurements result in \pm 0.63 and $0.33 \mathrm{~m}$ vertical error for the EM1002S and EM3002D, respectively, for a depth of $30 \mathrm{~m}$ (Tables 1,2). These intervals encompass all sources of errors originating from the suite of instrumentation used during acquisition.

Pitch, roll, heave and yaw were automatically compensated for during acquisition and a sound velocimeter constantly monitored the sound velocity at the transducers.
Table 1 EM3002D MBES specifications and auxiliary sensors

\begin{tabular}{ll}
\hline Parameters & Measure \\
\hline Central frequency & $300 \mathrm{kHz}$ \\
Number of beams & $508(254 / \mathrm{head})$ \\
Beam width & $1.5^{\circ} \times 1.5^{\circ}$ \\
Beam mode & Equidistant \\
Angular swath range & $200^{\circ}$ \\
Pulse length & $150 \mu$ s \\
Positioning systems & GPS Sercell, \\
& Furuno and RTK \\
& Thales \\
Motion sensor & Seatex MRU 5 \\
Sound velocity sensor & Valeport mini SVS \\
\hline
\end{tabular}

Survey lines were spaced to reach a good compromise between survey time/costs and quality of the data resulting in a minimum of $20 \%$ across-swath overlap between adjacent lines. Throughout the timespan of acquisition (inter- and intra-survey), the MBES settings controlled by the on-board software (i.e. SIS: Kongsberg native acquisition platform) remained unchanged (i.e. pulse length, beam aperture, beam spacing). The state of the antenna transducers was thoroughly checked and maintained for biofouling and deterioration of its components (either by divers or during regular dry-dock operations). Similarly, across all surveys, track lines were sailed in a SW-NE direction. Maintaining operational parameters stable and checking the physical state of the instrument ensured that instrumental drift was kept to the minimum.

Regarding sound absorption throughout the water column, the $\alpha$ coefficient (see Francois and Garrison 1982) was computed according to the local seawater properties at the surface which were fed into the acquisition system every half an hour. The necessary water medium environmental parameters were obtained from the On board Data Acquisition System (ODAS), which logs these data at 1-s intervals. No vertical profiles of the seawater properties were acquired since in this region the water mass is known to be well mixed throughout the year and no stratification is expected to occur (Luyten et al. 2003; van Leeuwen et al. 2015) and the surface values are considered to be sufficiently representative.

To verify instrumental drift on the medium to long term and allow comparison of backscatter levels in time, data were verified against an area with stable depth and backscatter levels ('KWGS' reference area, blue rectangle in Fig. 1). This calibration area $\left(1.8 \mathrm{~km}^{2}\right)$ is located in a gully in-between two sandbanks and is dominated by sand to sandy Gravel. These verifications showed that the oblique incidence backscatter [beam angle sector $\pm\left(35^{\circ}-45^{\circ}\right)$ and $\pm\left(0^{\circ}-70^{\circ}\right)$ for the full angular range] mean 
Table 2 Time-series dataset specifications

\begin{tabular}{llll}
\hline \multicolumn{4}{l}{ R Belgica } \\
\hline Survey & Time-layer-ID & Month-year & System \\
\hline ST2004 & $\mathrm{T}_{1}$ & April-2004 & EM1002S \\
ST2010 & $\mathrm{T}_{2}$ & February-2010 & EM3002D \\
ST1319 & $\mathrm{T}_{3}$ & July-2013 & EM3002D \\
ST1417 & $\mathrm{T}_{4}$ & June-2014 & EM3002D \\
ST1425 & $\mathrm{T}_{5}$ & October-2014 & EM3002D \\
ST1507 & $\mathrm{T}_{6}$ & March-2015 & EM3002D \\
ST1533 & $\mathrm{T}_{7}$ & December-2015 & EM3002D \\
\hline
\end{tabular}

values remained, per survey, within $1 \mathrm{~dB}$ around the overall mean BS level with no significant trend that would suggest instrumental drift.

\section{MBES data processing}

The backscatter strength (BS) quantifies the amount of acoustic intensity scattered back to the sonar receiver following a complex interaction of the transmitted signal with the seafloor. It is the result of an intricate combination of several physical factors: the seawater-seafloor impedance contrast, the interface roughness and the sediment volume heterogeneity, the signal incidence angle on the seafloor and the acoustical signal frequency (Lurton 2010). Due to the various scattering properties of different seafloor substrates, backscatter can help determine bottom type (e.g. de Moustier and Alexandrou 1991; Hughes-Clarke et al. 1996; Ferrini and Flood 2006) and possibly to infer some of its physical characteristics.

However, backscatter data are inherently noisy, showing strong amplitude fluctuations due to the very nature of the scattering process (Lurton 2010), and the possible presence of additive external noise: a first processing stage is to reduce this random fluctuating character by appropriate filtering techniques. A second category of processing aims to correct geometrical artefacts resulting from the characteristics of instrumentation used in the acquisition (i.e. motion and positioning sensors), the seabed geometrical configuration (dictated by the local topography), the velocity and absorption properties of the water medium within which sound is travelling, and the angle of incidence (Lurton and Lamarche 2015). The observed angular response of seafloor backscatter (describing how the reflectivity impact upon echo intensity varies with the incidence angle) can be categorised into three distinct angle sectors. Each are characterized by a different scattering regime (i.e. the specular or near-nadir, the oblique and the low-grazing angle regime), hence they can be treated as separate entities (i.e. statistical populations) (Lurton 2010). In order to produce a sedimentological meaningful image and avoid the along-track banding effect of the three domains, the resulting angular dependence must be compensated. Consequently, the backscatter strength has to be normalised to a conventional reference angle (ideally in the $30^{\circ}-60^{\circ}$ range, but typically $45^{\circ}$ is used).

Furthermore, several correction must be applied to the data, in order to account for the sonar sensor's responses: source levels and pulse length; acoustic transmission losses due to spreading and absorption; 3-D beam directivity patterns; sensitivity of the receiving arrays and electronics; and real-time time varying gain (TVG) corrections applied by the sounder. These various points were addressed in the real-time data reduction scheme applied in Kongsberg Maritime echosounders and during acquisition (Hammerstad 2000).

To allow consistency in the last phases of the data processing (i.e. mosaic production) and hence enable their subsequent inter-comparability (in terms of relative $\mathrm{dB}$ values expressing a reflectivity scale according to a common reference), the EM3002D data were subject to a standardised processing procedure following the BSWG recommendations (see Lurton and Lamarche 2015). Fledermaus Geocoder (FMGT, v7.4.5.b) and QPS QIMERA (v1.2.4.429a) software suites were used to process the MBES raw data. Initially, tide-corrected bathymetry was produced and exported as 1-m horizontal resolution raster (32-bit float files) and as sound density files for integration in FMGT. The bathymetric surfaces are used to correctly allocate the backscatter snippet traces from single pings to their true seabed position. Each survey was normalised by applying a flat angle varied gain (AVG) filter with a window size of 300. In order to weight nadir pixels and reduce their banding effect, the "No Nadir if Possible 2" algorithm and " $50 \%$ line blending" FMGT options were applied.

As such, the final dataset consisted of (1) relative (standardised to a common reference surface area) backscatter reflectivity (in $\mathrm{dB}$ ), and (2) bathymetric surfaces (m) at $1 \mathrm{~m}$ horizontal resolution. The EM1002S data did not prove to be comparable in terms of backscatter levels with those from the EM3002D system, due to the differing intrinsic properties of the sensors (i.e. electronics and hardware) and to the absence of a cross-calibration of both sensors. Consequently, the first campaign was not included in the pre- and ensemble classification analyses (in "Pre-classification" and "Ensemble approach classification").

\section{Ground-truth data}

The ground-truth data used in this study were acquired in complement to the $T_{7}$ survey. Collection of ground truth is necessary to validate the assumptions developed during the observation of acoustic data and ultimately to derive confidence metrics expressing the validity of the 
map produced. Ten samples were collected using a Van Veen grab, each with three replicas to ensure the spatial consistency of the acoustic theme being sampled.

Video samples were acquired by means of a dropframe, equipped with underwater lights and a camera with a $1 \times 1 \mathrm{~m}$ field of view. Video-frame data with poor visibility (i.e. due to turbidity or too strong current) were discarded. Visual sampling was very useful to acquire data in the gravel areas where conventional gears failed (i.e. box core and Van Veen). All sample coordinates were corrected for the DGPS antenna layback accounting for the main source of positional error and were mapped with a $10 \mathrm{~m}$ buffer.

Sample types were described by combining visual and expert observations with grain-size parameters calculated by a MALVERN Mastersizer 3000 instrument. To validate the consistency in terms of sediment classification versus backscatter levels, the classes' description was compared to previous substrate classification studies within the same area (Roche 2002).

Only features visible at the seafloor were described and classified into three thematic classes summarizing the main substrate composition: (1) homogeneous well-sorted fine to medium sand (fS); (2) moderately sorted medium sand with bioclastic detritus $(\mathrm{mS}+\mathrm{b})$; and (3) medium-to-coarse sand with gravel clusters (cS + G; Fig. 3).

As will be shown later (see Fig. 5 in "Supervised map of the study area"), the fS and $\mathrm{mS}+\mathrm{b}$ classes are texturally and sedimentologically similar with an overlap in terms of $\mathrm{dB}$ ranges, $\mathrm{mS}+\mathrm{b}$ being a subset of the $\mathrm{fS}$ class. This is likely explained by the presence of bioclastic detritus and a significant roughness in the $\mathrm{mS}+\mathrm{b}$ class which lead to interface scattering having a significant contribution to the overall acoustic return and causing a relatively high level $(\approx-27 \mathrm{~dB})$ of mean backscatter. On the contrary, the fS class, which is almost entirely distributed on top of the sandbank (in the most dynamic part of the study area, likely with a higher water content than the flank and gully areas) is very well sorted and homogenous, with little interface roughness and no surface scatterers, resulting in the lowest values $(\approx-31 \mathrm{~dB})$ of mean backscatter (Fig. 5). Conversely, the $\mathrm{cS}+\mathrm{G}$ class features the highest content of coarse material with sparse individual strong scatterers, and high roughness at the interface; hence it corresponds to the highest values $(\approx-22 \mathrm{~dB})$ of mean backscatter (Fig. 5). The described samples were separated into training $(2 / 3)$ and validation (1/3) sets (Table 3). Sample representativeness was

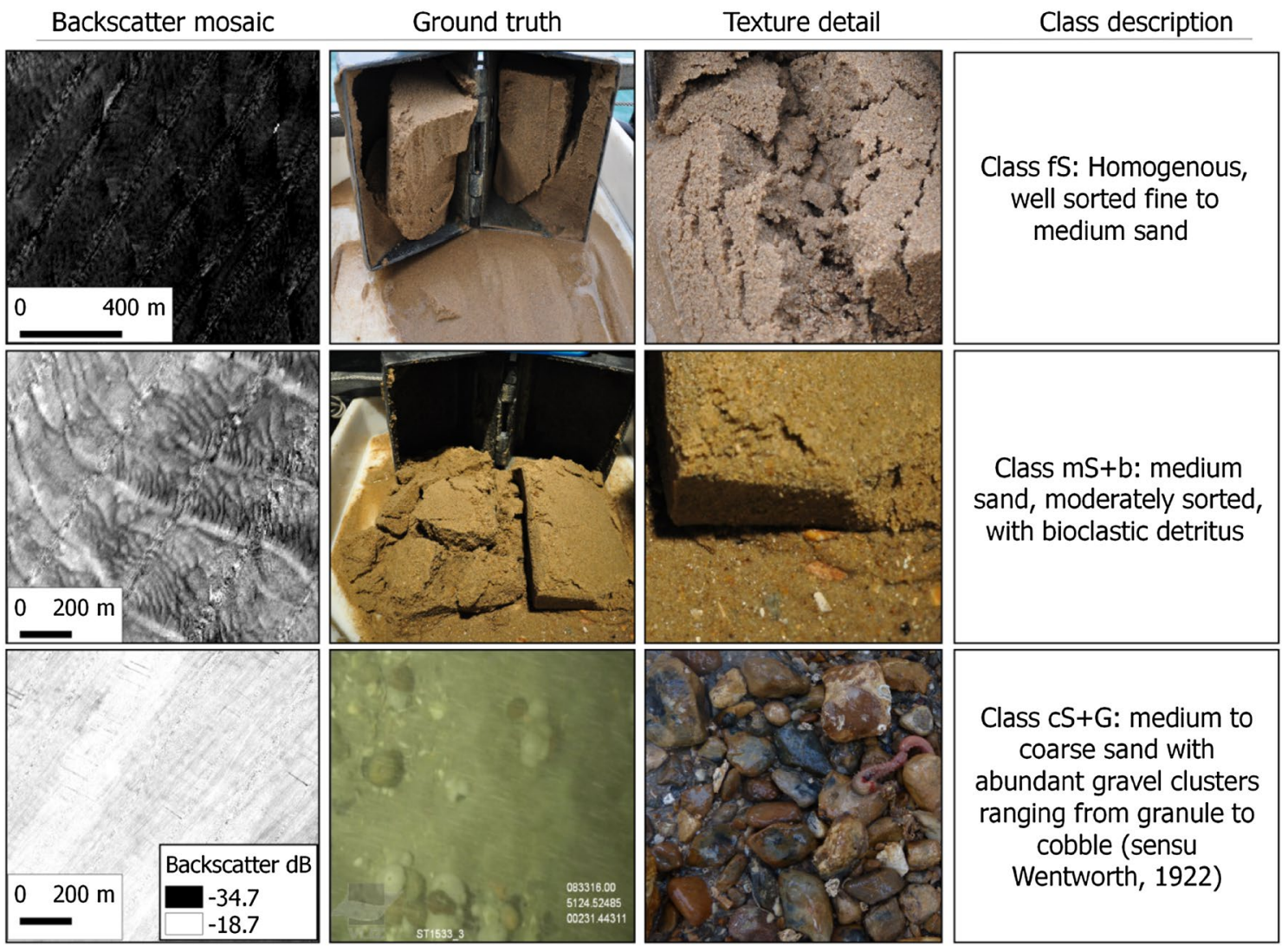

Fig. 3 Backscatter mosaic, ground-validation sample picture, textural detail and class description for the identified substrate classes 
Table 3 Summary of sample sets used ( $f S$ fine homogenous sand, $m S+b$ fine to medium sand with bioclastic detritus, $c S+G$ medium to coarse sand with gravel clusters, $V V$ Van Veen grab sampler)

\begin{tabular}{lcccl}
\hline Class_ID & Training & Test & N-samples & Gear \\
\hline fS & 9 & 5 & 14 & Grab (VV) \\
$\mathrm{mS}+\mathrm{b}$ & 4 & 2 & 6 & Grab (VV) \\
$\mathrm{cS}+\mathrm{G}$ & 6 & 4 & 10 & Video frame \\
Total & 19 & 11 & 30 & \\
\hline
\end{tabular}

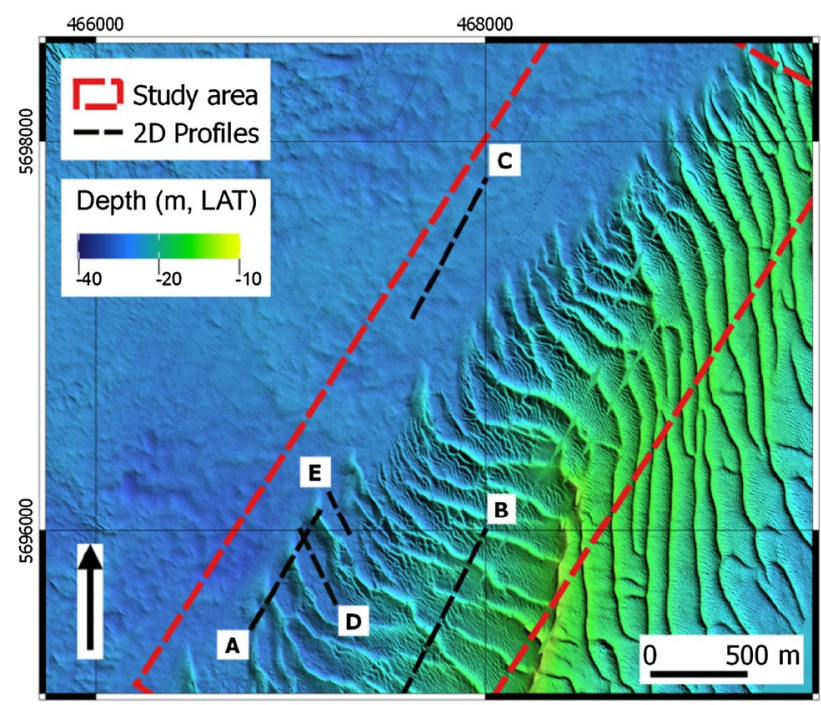

Fig. 4 Location of the 2D profiles selected for the analysis of morphological evolution

assessed visually by plotting the backscatter cumulative frequency distribution of the study area and for the mean backscatter values extracted within a $10 \mathrm{~m}$ buffer at the samples' locations.

\section{Morphological evolution}

At first, an assessment of the spatio-temporal morphological evolution is carried out to determine whether changes in substrate are due to morphological evolution (i.e. migrating dunes), to an actual reconfiguration of the substrate delineations or to a combination of both. Regions of interest (ROI) encompassing the main morphological and substrate features of the study area were selected to extract 2D profiles from the time series (see Fig. 4 for profile locations). Simple yes/no and quantitative metrics of change with information about the directionality (i.e. ebb or flood dominated bedforms) of the migration can be derived from here. For ease of interpretation, data from 2004 to 2015 were used only ( $\mathrm{T}_{1}$ and $\mathrm{T}_{7}$, Table 2$)$.

\section{Supervised classification}

The second phase of the analysis makes use of the most recent $\left(\mathrm{T}_{7}\right)$ acoustic survey for which complementary ground-truth data are available. In order to efficiently combine the two datasets, a supervised classification algorithm is used. Unlike an unsupervised method, where no a priori information about the class labels is provided to the algorithm (i.e. clustering procedures), supervised classification uses ground-truth information to train and test the classification results.

The Random Forest (RF; Breiman 2001) algorithm was used for classification. RF has high predictive accuracy in studies focusing on the comparison of supervised classifications of MBES data (Diesing et al. 2014; Diesing and Stephens 2015) and have proven highly successful in data mining research ( $\mathrm{Li}$ et al. 2016). As explained in Diesing et al. (2014) and $\mathrm{Li}$ et al. (2016), the main underlying assumption of this method is that the predictive power of multiple classification trees (the elemental unit of machine learning methods) is higher than that of a single tree. Bootstrapped samples from the training data are used to construct the individual trees in the forest introducing the first element of randomness. In turn, a random subset of the predictor features is used at the node splits throughout the construction of the model. The result is the construction of unique trees. Decisions about the class allocation (labelling) are made on the basis of majority votes of individual trees. After a feature selection procedure, the RF was run growing 501 trees and leaving the parameters as default. The routine was implemented in $\mathrm{R}$ ( $\mathrm{R}$ Development Core Team 2008) using the RandomForest package (Liaw and Wiener 2002).

\section{Feature selection}

A set of textural and morphometric predictor layers were computed from multibeam depth and backscatter grids (Table 4). Predictor layers are a set of variables (in this analysis terrain and texture attributes) derived from the MBES backscatter and bathymetry which are combined to the observed substrate type points (response variable) to predict the full-coverage seafloor map (Lecours et al. 2016). The relevance of the predictors was investigated by following the feature selection procedure provided by Kursa and Rudnicki (2010) using the Boruta RF wrapper function. Boruta identifies important variables by performing multiple runs of the RF classification (a total of 1000 runs were performed here) and by comparing the RF Z-scores of the original variables with the scores of their permuted copies (shadow variables). The Z-score is a measure expressing how many standard deviations a score stands from the mean. Higher importance is attributed when the mean 
Table 4 Predictor variables dataset with their description

\begin{tabular}{|c|c|c|c|}
\hline Layer & Description & Type & Software \\
\hline Backscatter strength (BS-dB) & $\begin{array}{l}256 \text { Grey level (NG) dynamic range } \\
\text { layer-the level of the acoustic energy } \\
\text { resulting from the scattering back to its } \\
\text { source of emission. Measured as the } \\
\text { ratio of the acoustic energy sent and } \\
\text { returned from the seafloor, referenced at } \\
1 \text {-m from the target at a given incidence } \\
\text { angle range }\end{array}$ & $\begin{array}{l}\text { MBES recorded seafloor backscatter } \\
\text { strength }\end{array}$ & FMGT-QPS \\
\hline Bathymetry (m) & Post-processed depth samples & MBES recorded seafloor depth & QIMERA—QPS \\
\hline Roughness (from depth) & $\begin{array}{l}\text { Difference between min. and max. of a } \\
\text { cell and its neighbours }\end{array}$ & Secondary morphometric derivative & $\begin{array}{l}\text { Rx64 (raster package; } \\
\text { Hijmans and van } \\
\text { Etten 2014) }\end{array}$ \\
\hline Contrast (BS) & $\begin{array}{l}\text { Differences of the intensities of the } \\
\text { instances within an image in a neigh- } \\
\text { bourhood }\end{array}$ & Secondary backscatter texture & $\begin{array}{l}\text { Rx64 3.2.3 (GLCM } \\
\text { package; Zvoleff, } \\
\text { 2015) }\end{array}$ \\
\hline Mean (BS) & Mean filter & Secondary filtered backscatter & Rx64 (GLCM package) \\
\hline Dissimilarity (BS) & $\begin{array}{l}\text { Degree of dissimilarity (Euclidean) in a } \\
\text { neighbourhood }\end{array}$ & Secondary texture & Rx64 (GLCM package) \\
\hline Moran (BS) & $\begin{array}{l}\text { Spatial auto-correlation in a neighbour- } \\
\text { hood }\end{array}$ & Secondary texture & Rx64 (raster package) \\
\hline Moran (from depth) & $\begin{array}{l}\text { Spatial auto-correlation in a neighbour- } \\
\text { hood }\end{array}$ & Secondary texture & Rx64 (raster package) \\
\hline Entropy (BS) & $\begin{array}{l}\text { Measure of spatial disorder in the distri- } \\
\text { bution of elements within the grey level } \\
\text { co-occurrence matrix }\end{array}$ & Secondary texture & Rx64 (GLCM pkg) \\
\hline
\end{tabular}

Software used for computation is also listed

Z-score of a variable after $n$ runs is significantly higher than $\mathrm{z}$-scores produced by the shadow variables.

\section{Model evaluation}

Overall accuracy $(A)$ and Kappa $(K)$ accuracy metrics were derived using the contingency table which cross-tabulates test and predicted instances (Foody 2004). Global accuracy provides a metric expressing the amount of correctly labelled pixels by the classifier whereas Cohen's Kappa reflects the difference between the overall agreement and the agreement expected by chance.

\section{Comparison of thematic maps}

Since the supervised information is to be extended to the broader time series of acoustic data for which there is no ground-validation data, an analysis similar to that of Ierodiaconou et al. (2005), in which supervised and unsupervised classifications are compared and evaluated for similarity, was applied. In this paper, $\mathrm{K}$ means was chosen as an unsupervised classification method due to its success in finding optimal clustering solutions and after comparing the RF classification to an array of unsupervised classifiers. Hartigan and Wong (1979) algorithm was implemented using the
R base functions (R Development Core Team 2008). Given a certain number of classes, the method seeks to reduce and maximise the within and between classes variance respectively by iteratively grouping similar points in their feature space. To validate the application of an unsupervised classifier, paired-pixel metrics of map agreements were computed after Foody (2004), Pontius and Millones (2011), and Pontius and Santacruz (2014). The R package diffeR was used (Pontius and Santacruz 2015). Components of allocation are used to derive the agreement between maps at the level of the entire landscape and per category. Quantity and Allocation describe the amount of change that is respectively due to the proportion of categories between reference and test instances and to the amount of spatial mismatch between categories.

\section{Change detection}

Three types of analysis were performed on the backscatter time series in order to extract trends and patterns of change in substrate classes: pre-, post- and ensemble-methods classification. Ensemble approaches combine supervised and unsupervised classifiers, whereas a pre-classification method focuses on the unclassified data values (similarly to directly relying on spectral bands in satellite imagery). The 
Fig. 5 a Backscatter distribution in the study area, and per sample dataset (ST1533- $\mathrm{T}_{7}$ dataset), $\mathbf{b}$ boxplot of mean backscatter extracted from a $10 \mathrm{~m}$ buffer at the ground-truth locations, c same as (a) using depth, d same as (b) using depth. Training and test refer to the distributions of the training and validation sample datasets used in the RF classification
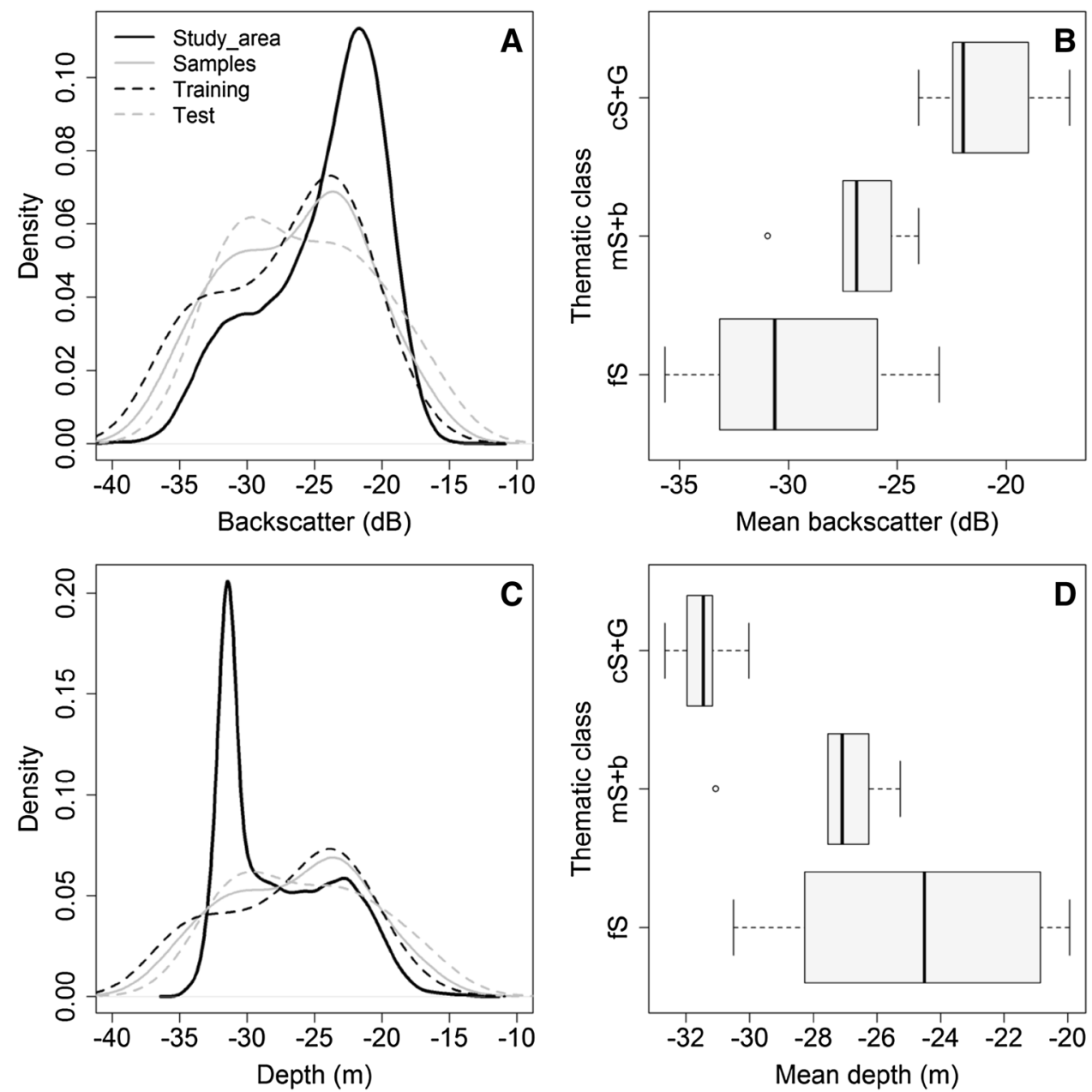

aim of a post-classification approach is to allocate classlabels to the data values to produce thematic maps.

\section{Pre-classification}

The pre-classification approach uses backscatter values taken from rectangular bins of the sampling locations representative of the different geomorphological and substrate features of the ROIs. Following, basic statistics and temporal trends were studied (for example, fluctuations around the $\pm 1 \mathrm{~dB}$ accuracy threshold; Hammerstad 2000). In order to detect outliers in the time series, sigma detections where chosen as the favoured statistical measure to quantify the dispersion of a set of data values.

\section{Ensemble approach classification}

An ensemble method, combining supervised and unsupervised classifications was also applied. K-means classes ( $\mathrm{dB}$ ranges) identified in $\mathrm{T}_{7}$ were used to reclassify the complete dataset for which ground-truth data were not available. From this classified dataset, proportion counts were extracted to observe temporal trends. Prior to transforming the successional backscatter mosaics into classified data, the Within Group Sum of Squared Distances plot was computed independently for each dataset. This ensured that the number of classes in each time series was maintained, and allowed testing. This also serves to test the class discrimination potential of data gathered at 100 and $300 \mathrm{kHz}$ from the EM1002S and EM3002D, respectively. This technique is similar to computing a silhouette plot where the optimal number and size of classes in a dataset becomes visible (Eleftherakis et al. 2012).

\section{Post-classification}

The post-classification approach made use of the most commonly employed tool in change detection used in remote sensing studies: the transition matrix (Pontius et al. 2004; Braimoh 2006; Rattray et al. 2013). In this analysis, two unsupervised seafloor maps (e.g. prior and after a natural or anthropogenic event) are cross tabulated to derive detailed statistics describing the temporal changes. Persistence and class swap dynamics, gross gains and losses, between time 
and between classes' transitions, as well as persistence ratios expressing the tendency of a category to undergo a certain change process were derived after Braimoh (2006). Swap is defined as the change in spatial location of a substrate type between times. The net change describes the difference in quantity of a substrate class between time 1 and time 2. Thus, swap describes changes in location, whereas net change reports changes in quantity. Gain and Loss describe an increase and decrease of the areal extent of a substrate class respectively. Gain $\left(G_{p}\right)$, Loss $\left(L_{p}\right)$ and Net $\left(N_{p}\right)$ to persistence ratios are derived as a measure of class tendency to the different types of transition. Values above 1 indicate that a class is more likely to gain or lose from other classes rather than persisting across the time scale analysed. Values close to 0 indicate little or absence of change. The net change to persistence ratio, $\mathrm{N}_{\mathrm{p}}$, indicates the overall trend of a category with negative and positive values indicating the directionality of the temporal trends.

\section{Results}

Firstly, results are presented on the supervised classification achieved by implementing the Random Forest algorithm. Secondly, the supervised model is compared to the map of the study area produced by the unsupervised clustering method. Next, the results from the two-dimensional morphological analysis are provided, followed by the change detection approaches tested on the time-series backscatter dataset.

\section{Supervised map of the study area}

Figure 5 shows the visual validation of the sample datasets. This showed an overall good representation of the BS variation in the study area (Fig. 5a). Mean backscatter values, extracted within $10 \mathrm{~m}$ circular buffers at the sample's positions, indicate good separation of the classes (Fig. 5b) where coarse-hard and fine-soft classes exhibit the highest and lower backscatter values respectively. Similarly, the separation using the bathymetry evidences the distribution of substrate types within different depth zones (i.e. fS on the top of the sandbank, $\mathrm{mS}+\mathrm{b}$ transiting to the deepest area, and $\mathrm{cS}+\mathrm{G}$ in the gully; Fig. 5c, d). The predicted substrate classes' distribution by the Random Forest supervised classification is shown in Fig. 6 b.

The most important variables selected by the feature selection tool were BS, BS $3 \times 3$ mean filter, BS Local Moran and bathymetry. With these selected features, the map produced has an overall accuracy (A) of $81 \%$. Furthermore, more than $70 \%$ of the classification did not occur by chance $(\mathrm{k}=73 \%)$.
Comparison between supervised and unsupervised models

Figure 6 shows the visual agreement between supervised and unsupervised classifications, while agreement metrics between these models are summarised in Table 5. Overall, agreement is high with an overall quantity and allocation difference $<10 \%$. In terms of quantity, classes differ by an overall of $0.42 \%$. The larger differences result as allocation disagreement of 9.47 and $8.16 \%$ for $\mathrm{mS}+\mathrm{b}$ and $\mathrm{cS}+\mathrm{G}$ classes respectively. The fS class is by far experiencing the highest between-map agreement (Table 5) with 1.1 and 0.42 differences in allocation and quantity respectively.

\section{Morphological changes}

To characterize the dynamics over the full period, depth profiles were extracted from the ROIs for $2004\left(\mathrm{~T}_{1}\right)$ and 2015 ( $\mathrm{T}_{7}$; Fig. 7). Within the barchanoid dunes and along the top sand bank areas (Fig. 7a, b respectively) horizontal migration accounts for up to $\approx 40 \mathrm{~m}$ with a SW-NE directionality. Considering the in-between surveys, it is possible to observe a progressive migration, advancing of ca. $20 \mathrm{~m}$ from 2004 to 2010 , ca. $10 \mathrm{~m}$ from 2010 to 2013 and less than $5 \mathrm{~m}$ progressively throughout the remaining surveys up until late 2015. Within the relatively flat and gravelpopulated areas (Fig. 7c, d, f), devoid of dunes, the seabed shows an overall stability. In these areas, vertical changes or aggradation was observed, but cannot be confirmed as they remain within the IHO Order S and $1 \mathrm{~A}$ confidence envelopes. Nonetheless, a loss of profile complexity is observed between the two campaigns.

\section{Change detection}

\section{Pre-classification}

The boxplot analysis carried out by extracting backscatter data from the selected ROIs is shown in Fig. 8. Excluding the EM1002S data (not comparable in terms of insonification values), no significant trends are observable with the exception of zones A and C (transitional and gully zones of the study area) which exhibit deviations $>1 \sigma$ and generally a decreasing trend up until late $2014\left(\mathrm{~T}_{5}\right)$. Noticeably, all selected regions follow an overall elliptical trend (visible in Fig. 8h) and re-establish to the initial state of February $2010\left(T_{2}\right)$ by December 2015. Throughout all cases, the spread is lower than $1 \mathrm{~dB}$ evidencing no statistically significant changes. Testing this hypothesis, the reduced $\chi^{2}$ test computed within each region shows that a significantly negative trend in backscatter spatio-temporal behaviour does not exist $\left(\chi^{2} \ll 1\right)$. 
Fig. 6 a K means unsupervised classification, b Random Forest supervised classification and c map of overall agreement between classifications

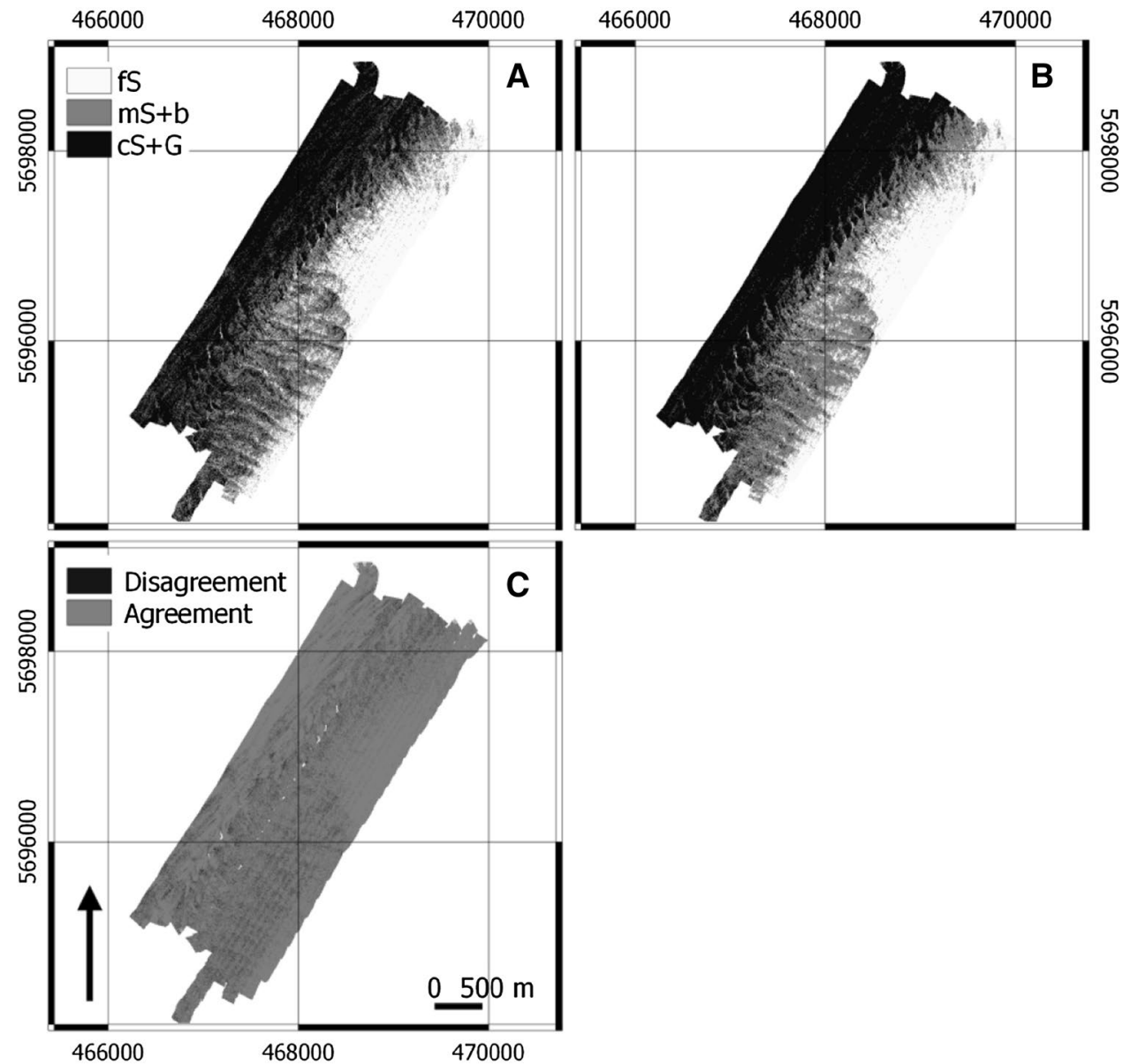

Table 5 Components of difference, allocation and quantity, between models predicted by the Random Forest and K-means (pixels in percentage)

\begin{tabular}{lllll}
\hline Differences/class & Overall & $\mathrm{fS}$ & $\mathrm{mS}+\mathrm{b}$ & $\mathrm{cS}+\mathrm{G}$ \\
\hline Difference & 9.79 & 1.52 & 9.78 & 8.28 \\
Allocation & 9.37 & 1.1 & 9.47 & 8.16 \\
Quantity & 0.42 & 0.42 & 0.31 & 0.12 \\
\hline
\end{tabular}

\section{Ensemble approach classification}

Class proportion counts per survey were extracted from the classified EM3002D dataset (ensemble approach) and are shown in Fig. 9. Temporal trends' and classes' relationships are shown for the entire study area, as well as for the three selected gravel refugia. The fS class appears to be relatively stable across all instances and survey. An inversely correlated relationship is evident between $\mathrm{cS}+\mathrm{G}$ and $\mathrm{mS}+\mathrm{b}$ classes. This is also shown in Fig. 10 where the proportion counts per survey are plotted against each other.

At the level of the entire study area (Fig. 9d), and similarly to the pre-classification analysis, this method indicates that the class proportions return to their original state. On the contrary, within the gravel refugia zones (Fig. 9a-c), the $\mathrm{cS}+\mathrm{G}$ class experiences a net loss in favour of finer substrate types with no indication of re-establishment to a previous state.

\section{Post-classification}

The bi-temporal transition matrix, cross-tabulating the relationships between thematic instances present within the classified maps of $2004\left(\mathrm{~T}_{1}\right)$ and $2014\left(\mathrm{~T}_{4}\right)$ is presented in Table 6. Persistence is denoted along the diagonal whereas off-diagonal entries are from-to transitions. Over $50 \%$ of the substrate remains static between the classifications. This is mainly driven by persistence of the $\mathrm{mS}+\mathrm{b}$ and $\mathrm{cS}+\mathrm{G}$ classes (with 27 and $20 \%$ persistence respectively). The class fS experienced the lowest persistence (7.6\%) evidencing mostly the dynamics of the bedforms (see Fig. 11A where gains and losses result from the migration of dune crests).

Following a more detailed inspection of the matrix, ratios describing class tendencies to persistence, gains and losses, swap and net change dynamics were computed 
Fig. 7 Depth profiles extracted from the digital elevation model time series. a Barchanoid dunes area, $\mathbf{b}$ top sand bank, $\mathbf{c}$ gully area, $\mathbf{d}$ gravel refugium 2 , and e gravel refugium 3. Blue and red envelopes in $\mathbf{d}, \mathbf{e}$ are the \pm IHO confidence intervals for the EM1002S and EM3002D surveys respectively
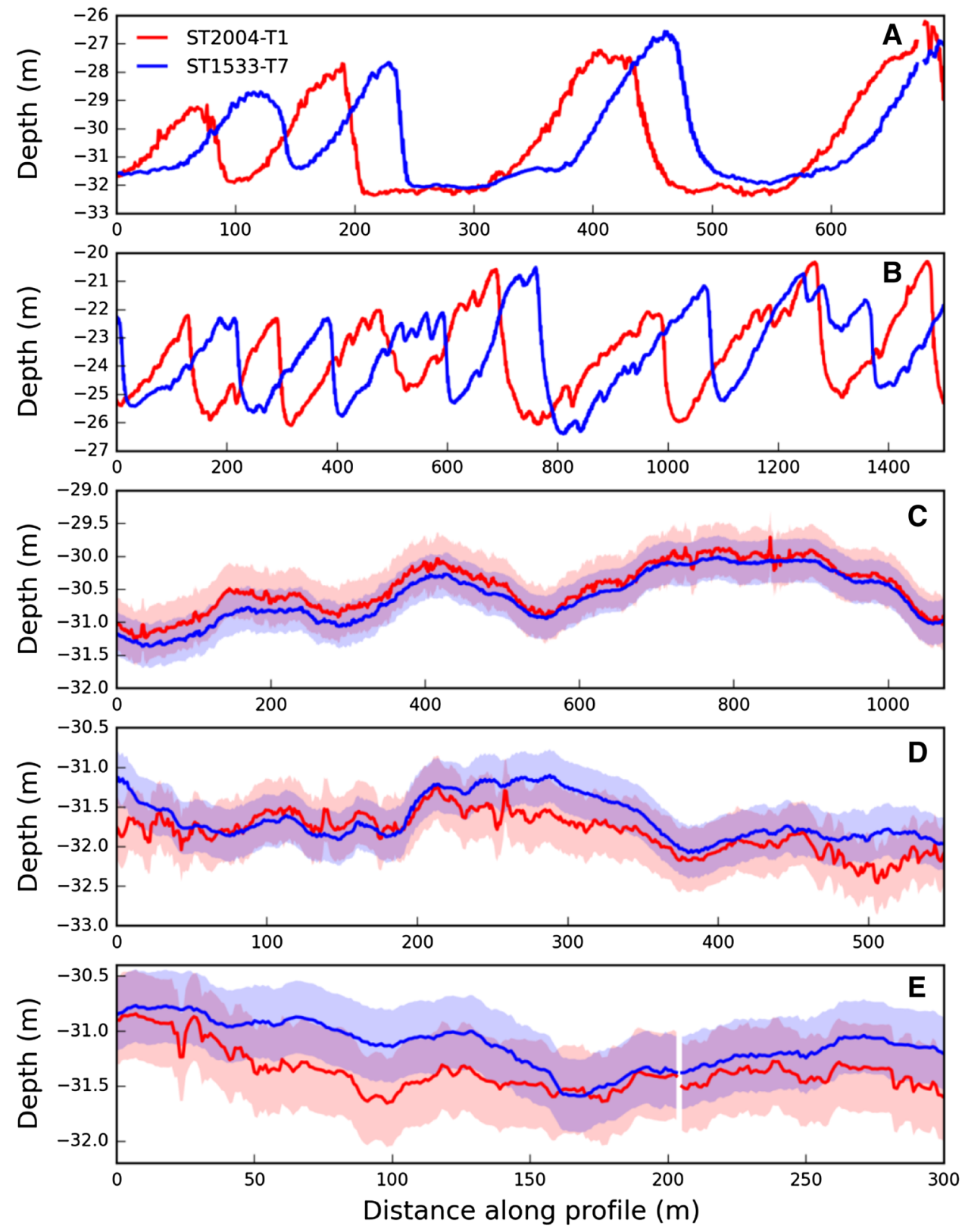

(Table 7). Gains, losses and persistence changes are illustrated in Fig. 11 where their reciprocal relationships are observable; in particular between $\mathrm{mS}+\mathrm{b}$ and $\mathrm{cS}+\mathrm{G}$ classes in the North-Eastern part of the study area (see Fig. 11B where the $\mathrm{mS}+\mathrm{b}$ class gains in favour of the $\mathrm{cS}+\mathrm{G}$ class, forming ripple marks). All classes experienced a net gain in quantity between the 2 years except for the $\mathrm{cS}+\mathrm{G}$ class which experienced a net loss of $7.5 \%$ [see Fig. $11 \mathrm{C}$ where it is visible that within a selected refugium, the loss is depicted, partly due to bedform migration (SW) and partly due to the appearance of the $\mathrm{mS}+\mathrm{b}$ class within the flat and gravelly portion of this area (NE)]. Subtracting the net change from the total change derives swap dynamics. Of the total change for all classes, $83 \%$ results as swap; losses in a substrate class are replaced by gains in another substrate class. The $\mathrm{mS}+\mathrm{b}$ class experienced the highest gain $(21.41 \%)$, as well as the greatest loss $(21.14 \%)$ implying that most of the change attributable to this class is due to swap in location. Proportionally, 99.3, 72.5 and $65.3 \%$ of changes are attributable to swap for $\mathrm{mS}+\mathrm{b}, \mathrm{cS}+\mathrm{G}$ and fS classes respectively. The gain, loss and net changes are compared to the Persistence (diagonal elements of Table 6; calculated after Braimoh 2006) in order to derive ratios (respectively $G_{p}, L_{p}$ and $N_{p}$ ) providing a measure of class tendency to types of transition. Values above 1 indicate that a class is more likely to gain or lose from other classes rather than persisting between classified instances. Values close to 0 indicate little or absence of change. The fS class 

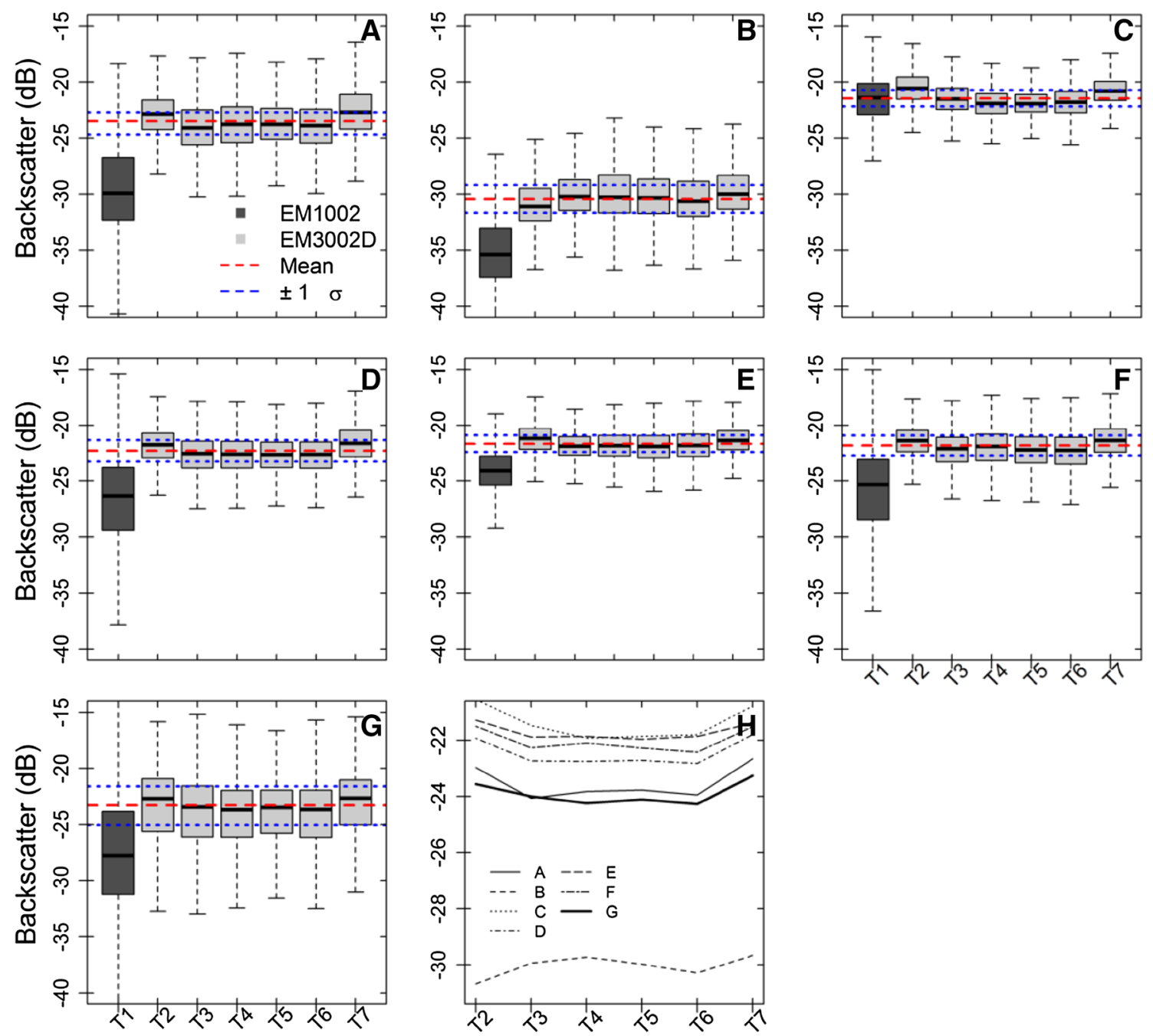

Fig. 8 Boxplot analysis for the entire time series $\left(T_{1}-T_{7}\right)$. Mean and standard deviation values were calculated from the EM3002D dataset only. a Barchanoid dunes area, b top sand bank, $\mathbf{c}$ gully area, $\mathbf{d}$ gravel refugium 1 , e gravel refugium 3 , f gravel refugium 4 , $\mathbf{g}$ entire

has the highest $G_{p}$ value: it has a high tendency to gain. The $\mathrm{mS}+\mathrm{b}$ class has similar $G_{p}$ and $L_{p}$ ratios, evidencing the high percentage of swap in this class. Most striking is the negative $N_{p}$ ratio and the high $L_{p}$ of the $\mathrm{cS}+\mathrm{G}$ class.

\section{Discussion}

\section{Multibeam backscatter in a monitoring context}

The basic premise in using MBES backscatter data for seafloor change detection is that changes in substrate cover must result in changes in backscatter values and changes in backscatter due to seafloor cover change must be large with respect to changes caused by other factors (readapted from Singh 1989) such as sea conditions, sensor's study area, and $\mathbf{h}$ mean backscatter values for the EM3002 time series $\left(\mathrm{T}_{2}-\mathrm{T}_{7}\right)$, within each ROI. For $\mathbf{a}-\mathbf{g}$ red and blue dotted lines represent weighted mean and $\pm 1 \sigma$ error respectively. For the ROIs location the reader is referred to Fig. 1 ( $A-F$ boxes)

intrinsic characteristics, changes in on-board acquisition parameters, vessel speed and direction of survey (Rattray et al. 2013; Lurton and Lamarche 2015). As such, verification of MBES backscatter stability is critical and should be controlled (Anderson et al. 2008). In this study, these limitations were mostly overcome as the dataset used was acquired by maintaining rigorous standards of acquisition and processing, including careful attention on environmentally dependent transmission losses (i.e. by regular control of absorption coefficient). To verify instrumental drift on the medium to long term, the trend in backscatter levels was compared against a time series in backscatter levels at a known reference area (KWGS reference area; Blue Polygon in Fig. 1; Roche et al. 2016). As such, average backscatter levels of the RV Belgica EM3002D could be compared from one survey to another during a similar period 
Fig. 9 Class proportions during each survey extracted from the classified dataset for three gravel refugia stations $(\mathbf{a}-\mathbf{c})$ and the entire study area (d). For the refugia's location the reader is referred to points $D, E$ and $F$ in Fig. 1
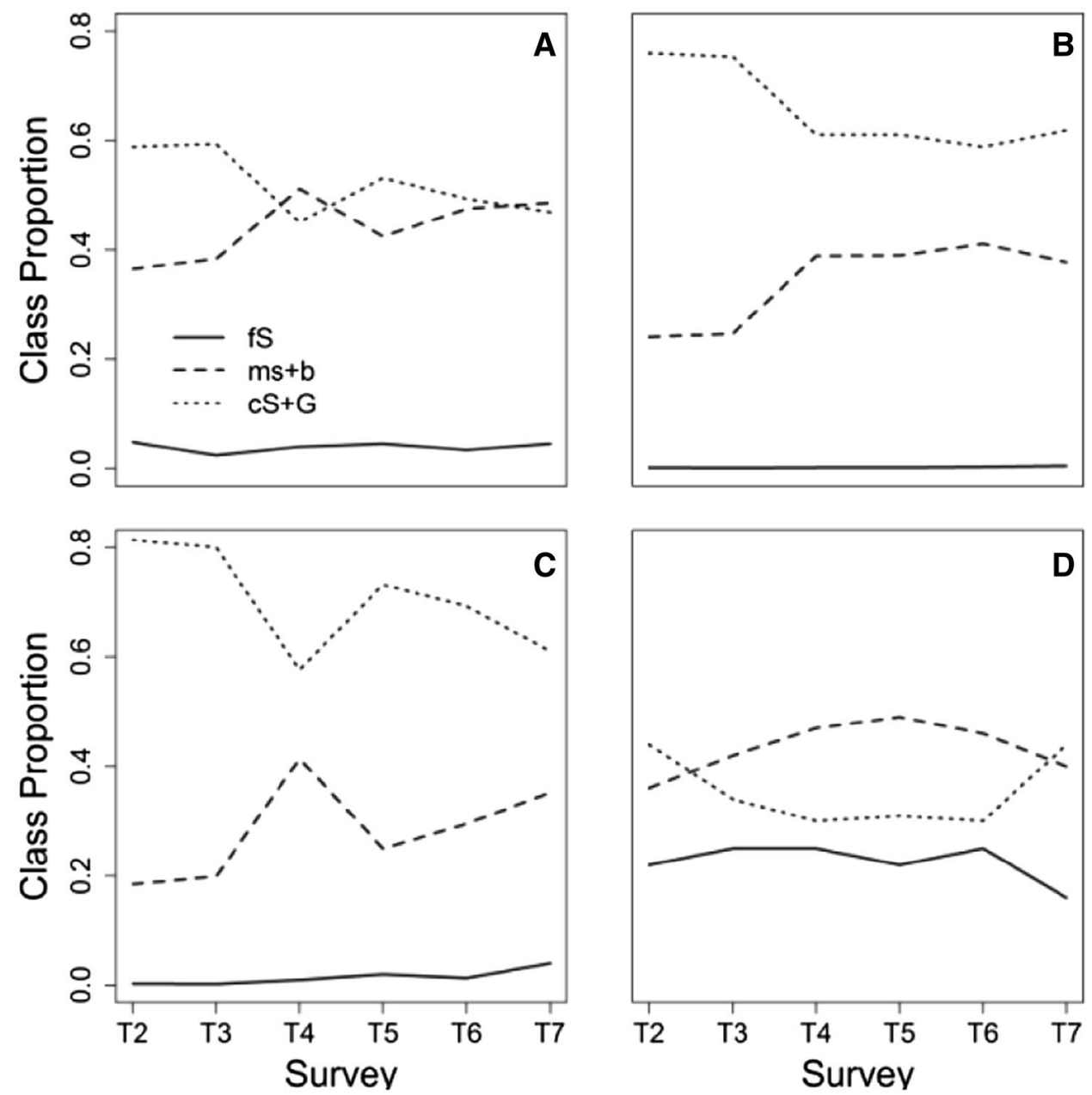

and allowed obtaining a dataset with temporally consistent $\mathrm{dB}$ ranges (yet relative).

However, changing environmental factors and seabed conditions may affect the backscatter values also. The effect of biological activity, which is seasonally driven and linked to the spawning and recruitment period of benthic species, is probably the most prominent factor. From literature, it is known that megabenthic zoo- and/or phytobenthic structuring species can be responsible for significant changes in the acoustic signal (e.g. Demosponges and Submerged Aquatic Vegetation, brittle stars; Montereale-Gavazzi et al. 2016; Holler et al. 2016), but also the occurrence of soft substrata macrobenthos ecosystem engineers such as tubeworms and some bivalves (e.g. Degraer et al. 2008; Van Lancker et al. 2012). Hitherto, the impact on the actual backscatter levels is poorly quantified and more research is needed on this aspect in a monitoring context. Beside changes due to the successional stages of some benthic species, natural variability in sediment deposition and erosion can also affect the backscatter level. This will depend on the hydrodynamics of an area, as well as on the sediment availability. Collection of tightly spaced acoustic surveys would be ideal to have a better control on the driving forces which would support the interpretation of trends in backscatter levels. In this study, the time lag between surveys was rather irregular which complicated distinguishing changes from natural versus anthropogenically-steered events. The combination of morphological analyses with backscatter change analyses is important in this regard.

\section{Change detection methods}

The pre-classification analysis of the backscatter time series indicated that within the selected regions of interest, no significant changes in seabed substrate could be detected across the timespan analysed. Since the first dataset was recorded with a former-generation echosounder, which was not cross-calibrated with the EM3002D and using a different frequency range, the values derived could not be directly compared in terms of the range in insonification values. The only evident behaviour in the data was in the barchanoid and gravel gully regions where locally, the mean backscatter level fluctuated around the $1 \sigma$ deviation (Fig. 8a, c). 
Fig. 10 Linear regressions between proportions of $\mathrm{cS}+\mathrm{G}$ and $\mathrm{mS}+\mathrm{b}$ classes for the gravel refugia stations $(\mathbf{a}-\mathbf{c})$ and the entire study area (d). Dotted lines $95 \%$ confidence limits. For the refugia's location the reader is referred to points $D, E$ and $F$ in Fig. 1
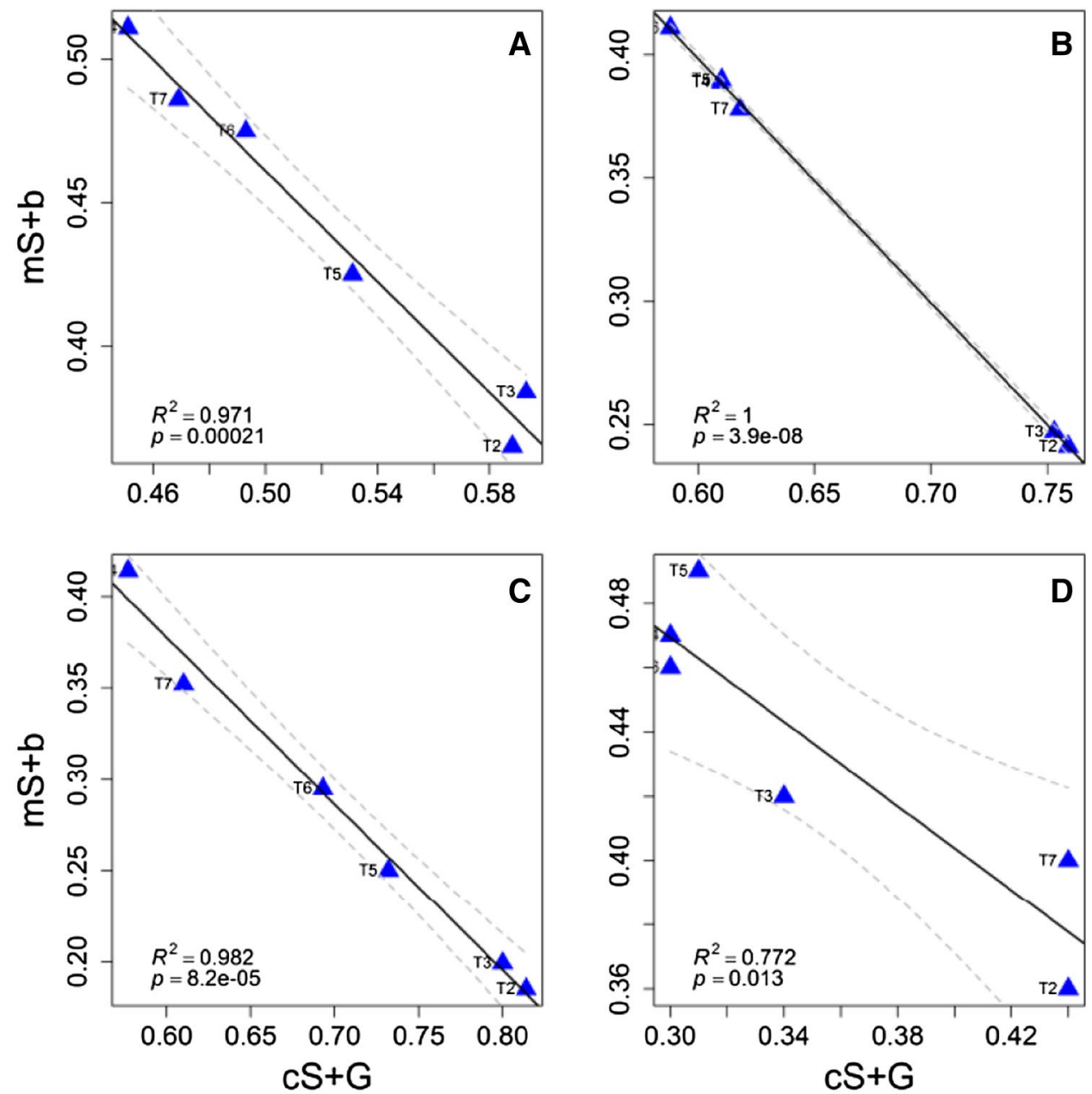

Table 6 Raw Confusion matrix rounded to two decimals cross tabulating the classified instances in 2004 and 2014 thematic maps

\begin{tabular}{lrrr}
\hline $2004 / 2014$ & \multicolumn{1}{c}{ fS } & $\mathrm{mS}+\mathrm{b}$ & $\mathrm{cS}+\mathrm{G}$ \\
\hline $\mathrm{fS}$ & $\mathbf{7 . 6 3}$ & 5.89 & 1.05 \\
$\mathrm{mS}+\mathrm{b}$ & 12.22 & $\mathbf{2 6 . 7 9}$ & 8.92 \\
$\mathrm{cS}+\mathrm{G}$ & 1.99 & 15.53 & $\mathbf{2 0 . 0 3}$ \\
\hline
\end{tabular}

Bold denotes either accuracy or persistence depending on the case

Since the comparison is rather focused on the spatial delineation and areal extent of the substrate classes rather than the intrinsic, physical characteristics of a circumscribed area, the post-classification methods, as adopted similarly to Rattray et al. (2013), did allow comparing data from different echosounders, and acquisition parameters. This was also possible due to the agreement in the number and size of classes discriminated by the two echosounders. The approach revealed information on the behavioural tendencies of certain substrates to undergo a certain change such as the negative trend of the hard substrate class and gain of the finer substrates.

In this study, there was a high agreement between supervised and unsupervised models, using quantity and allocation agreement/disagreement metrics, which allowed extending the analysis to the entire time-series dataset. As such, the initially ground-validated information could be fully exploited and extended to the full backscatter dataset. Substrate class proportions over time could be extracted so that global changes could also be accounted for. This is unlike the pre-classification approach that is limited to selected sub-areas where backscatter levels were extracted from. Therefore, the ensemble approach combined supervised and unsupervised classification algorithms (similarly to Ierodiaconou et al. 2005) which allowed using one ground-truth dataset to train a classification that was subsequently applied to the whole time series. This is a big advantage since sampling of each time series is most often not realistic given survey time and cost restrictions. Here, application of consistent data acquisition and processing allowed the comparability of instant statistical analysis results at various times. 

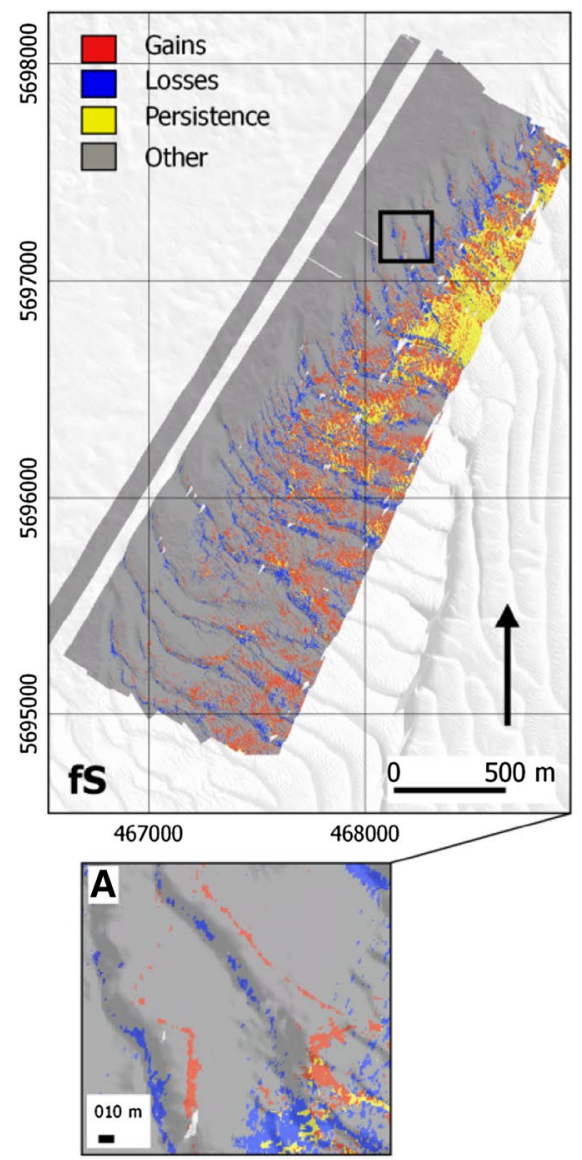
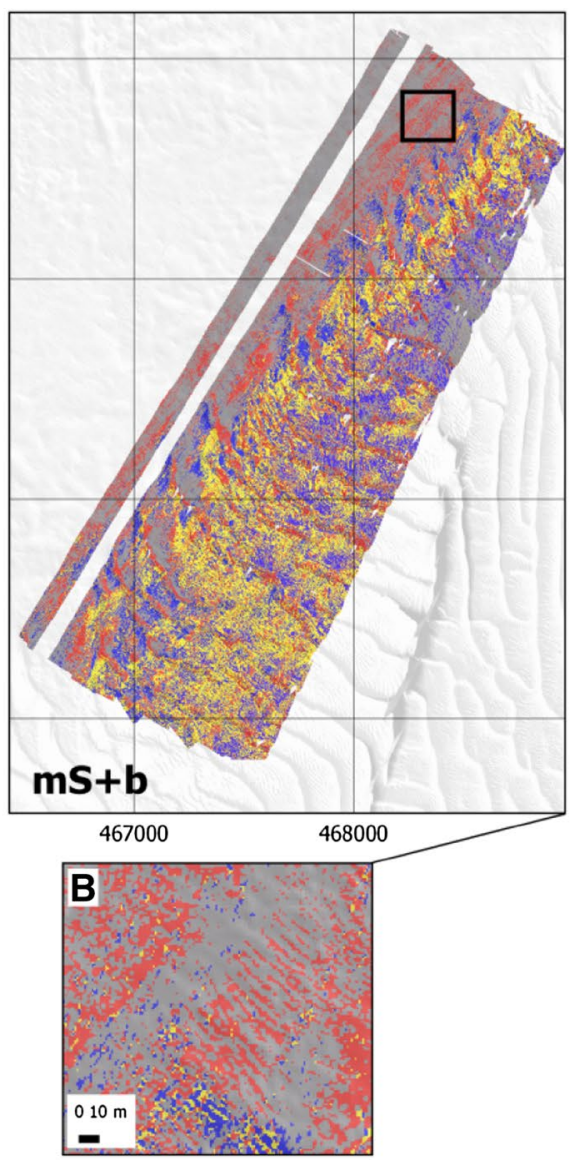
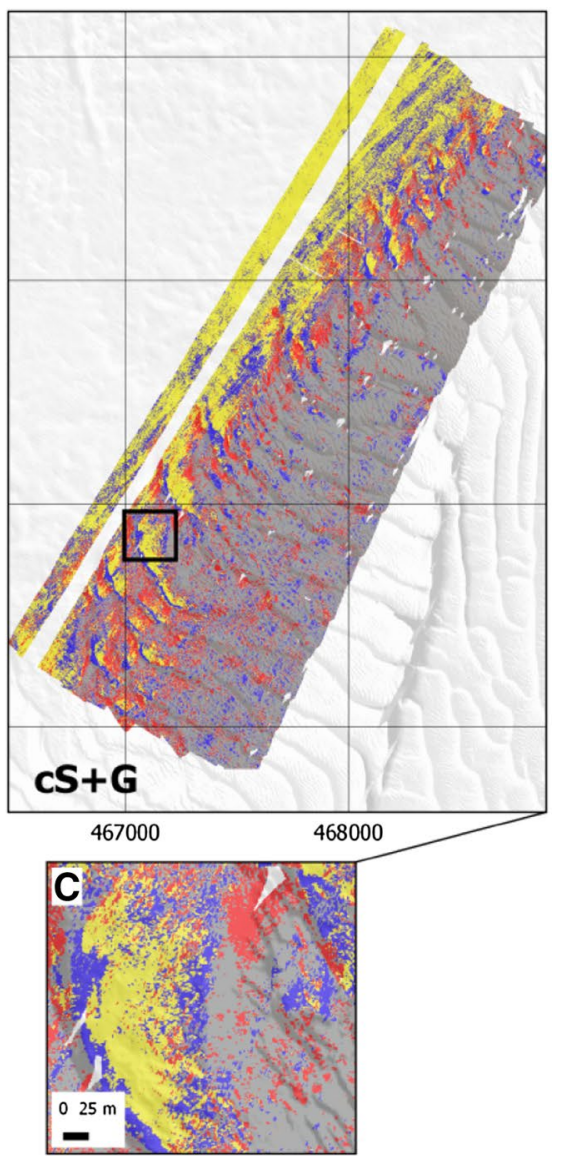

Fig. 11 Map representation of persistence, gains and losses for each class in the study area overlapping between $T_{1}$ and $T_{5}$

Table 7 Summary of the changes between 2004 and 2014 (in percentage and expressed as ratios)

\begin{tabular}{|c|c|c|c|c|c|c|c|c|c|c|}
\hline Class & Total 2014 & Total 2004 & Gain & Loss & Total change & Net (quantity) & Swap (location) & $\mathrm{N}_{\mathrm{p}}$ & $\mathrm{G}_{\mathrm{p}}$ & $\mathrm{L}_{\mathrm{p}}$ \\
\hline fS & 21.83 & 14.56 & 14.21 & 6.94 & 21.15 & 7.27 & 13.87 & 0.96 & 1.87 & 0.91 \\
\hline $\mathrm{mS}+\mathrm{b}$ & 48.2 & 47.92 & 21.41 & 21.14 & 42.55 & 0.28 & 42.28 & 0.02 & 0.8 & 0.79 \\
\hline $\mathrm{cS}+\mathrm{G}$ & 29.99 & 37.53 & 9.97 & 17.51 & 27.48 & -7.55 & 19.93 & -0.38 & 0.5 & 0.88 \\
\hline Total & 100 & 100 & 45.59 & 45.59 & 91.18 & 15.1 & 76.08 & & & \\
\hline
\end{tabular}

Accordingly to recent research ( $\mathrm{Li}$ et al. 2016), it was shown that the Random Forest classifier is a highly valuable tool for seafloor applications, producing accurate models and providing information on the most important feature layers used in the classification. Similarly to Diesing et al. (2014), backscatter was by far the most important variable for seafloor substrate discrimination (with highest Boruta Z-score after 1000 runs). Depending on the method applied, the accuracy of the change detection is strictly dependent on the accuracy of the classified maps used in the assessment and on the stability of the repeated observations.

\section{Application within a MSFD context}

By classifying the data, it was shown that from before the start of dredging activities $\left(T_{1}\right)$, northwards of the study area, to just after the peak of marine aggregate extraction $\left(\mathrm{T}_{5}\right)$, the gravel class progressively decreased at the level of the entire study area, including a net loss of the gravel class extent within the defined ecologically noteworthy areas (Fig. 1, black outlined polygons). From this, the ratio of hard versus soft substrata (Belgian MSFD indicator on seafloor integrity) first showed a negative trend, at least after the peak of the extraction activity, followed by a positive trend indicating a recovery process. Based on the depth 
time series, a morphological analysis revealed that part of the change is attributable to bedform migration of which the drivers require further investigation. An aggradational trend in the gravel areas was suggested from the observations, though this fell within the IHO confidence limits used. Despite this, changes in the depth profile depicted a reduction in seafloor complexity considering the surveys before and after the initiation of intense marine aggregate extraction.

A methodological framework to unambiguously link changes to pressures is under development and is yet hampered by a lack of data and knowledge on the natural variability and resilience of offshore sedimentary systems. Nevertheless, the present results are highly significant from an ecological perspective and necessitate a further investigation of the substrate evolution. If indeed smothering and/or deposition events would be more persistent under increased anthropogenic pressure, this may affect several ecosystem states and functions: e.g. reduction of sessile bio-encrusting epifauna; loss of surficial complexity leading to reduced micro-roughness; burial of biogenic clastic material; and overall reduced potential of bentho-pelagic coupling (Watling and Norse 1998; Hewitt et al. 2005).

\section{Conclusion}

This study highlights the importance of researching approaches and testing tools usable for local- and regionalscale environmental assessments (i.e. for MSFD implementation). A selection of useful methodologies was presented to detect changes in seafloor substrate types. The investigation showed how under specific standardised multibeam backscatter acquisition procedures, the confidence of repeated acoustic observations could be enhanced significantly and how the valuable, but expensive groundtruth information could be propagated from one survey to a time-series dataset via the application of supervised and unsupervised classification routines. The serial backscatter dataset was analysed using techniques developed in the remote sensing terrestrial realm showing that the methodologies are applicable for marine environmental monitoring. This is most promising for before and after control impact (BACI) type of assessments and such datasets would inevitably increase our understanding of anthropic impacts over an area. Although the methods presented were tested at local scales, they are repeatable and can be applied to broad-scale geographical extents; a major limitation being the need to collect large-scale datasets covering entire jurisdictional areas.

Acknowledgements This paper is a contribution to the projects MOZ4 (Flemish Authorities, Agency Maritime Services and Coast,
Coast, contract 211.177), INDI67 (BELSPO, contract BR/143/A2/ INDI67), ZAGRI, a federal Belgian programme for the continuous monitoring of sand and gravel extraction, paid from private revenues, and TILES (BELSPO, contract BR/121/A2/TILES). Ship time $R V$ Belgica was provided by BELSPO and RBINS-OD Nature. The Renard Centre of Marine Geology of Ghent University (RCMG) is acknowledged for the use of the sediment analysis facilities and instruments. Flanders Marine Institute (VLIZ) is acknowledged for the use of the video frame. Flanders Hydrography is acknowledged for the use of background bathymetric data. Two anonymous reviewers are acknowledged for their useful comments and improvements on the initial manuscript.

Open Access This article is distributed under the terms of the Creative Commons Attribution 4.0 International License (http:// creativecommons.org/licenses/by/4.0/), which permits unrestricted use, distribution, and reproduction in any medium, provided you give appropriate credit to the original author(s) and the source, provide a link to the Creative Commons license, and indicate if changes were made.

\section{References}

Anderson JT, Van Holliday D, Kloser R, Reid DG, Simard Y (2008) Acoustic seabed classification: current practice and future directions. ICES J Mar Sci 65:1004-1011

Ashley GM (1990) Classification of large-scale subaqueous bedforms: a new look at an old problem-SEPM bedforms and bedding structures. J Sediment Res 60:160-172

Belgian State (2012) Determination of good environmental status and establishment of environmental targets for the Belgian marine waters. Federal Public Service Health Food Chain Safety and Environment. https://www.health.belgium.be/sites/default/ files/uploads/fields/fpshealth_theme_file/19087665/Goede $\% 20$ milieutoestand-MSFD\%20EN.pdf. Accessed 18 Nov 2016

Braimoh AK (2006) Random and systematic land-cover transitions in northern Ghana. Agric Ecosyst Environ 113:254-263

Breiman L (2001) Random forests. Mach Learn 45:5-32

de Moustier C, Alexandrou D (1991) Angular dependence of 12-kHz seafloor acoustic backscatter. J Acoust Soc Am 90:522-531

Degraer S, Moerkerke G, Rabaut M, van Hoey G, Du Four I, Vincx M, Henriet JP, Van Lancker V (2008) Very-high resolution sidescan sonar mapping of biogenic reefs of the tube-worm Lanice conchilega. Remote Sens Environ 112:3323-3328

Diesing M, Stephens D (2015) A multi-model ensemble approach to seabed mapping. J Sea Res 100:62-69

Diesing M, Green SL, Stephens D, Lark RM, Stewart HA, Dove D (2014) Mapping seabed sediments: comparison of manual, geostatistical, object-based image analysis and machine learning approaches. Cont Shelf Res 84:107-119

EC (1992) Council directive 92/43/EEC of 21 May 1992 on the conservation of natural habitats and of wild fauna and flora, OJ, L 206, 22/07/1992, 7-5. http://eur-lex.europa.eu/legal-content/en/ TXT/?uri=CELEX\%3A31992L0043. Accessed 10 Nov 2016

EC (2008) 2008/56/EC of the European Parliament and of the Council of 17 June 2008 establishing a framework for community action in the field of marine environmental policy (Marine Strategy Framework Directive) (Text with EEA relevance). http://eurlex.europa.eu/legal-content/EN/TXT/PDF/?uri=CELEX:32008 L0056\&qid $=1492697872524 \&$ from $=$ en. Accessed 10 Nov 2016

Eleftherakis D, Amiri Simkooei A, Snellen M, Simons DG (2012) Improving riverbed sediment classification using backscatter 
and depth residual features of multi-beam echo-sounder systems. J Acoust Soc Am 131:3710-3725

Ferrini VL, Flood RD (2006) The effects of fine-scale surface roughness and grain size on $300 \mathrm{kHz}$ backscatter intensity in sandy marine sedimentary environments. Mar Geol 228: $153-172$

Foody GM (2002) Status of land covers classification accuracy assessment. Remote Sens Environ 80:185-201

Foody GM (2004) Thematic map comparison. Photogram Eng Remote Sens 70:627-633

Francois RE, Garrison GR (1982) Sound absorption based on ocean measurements: part II: boric acid contribution and equation for total absorption. J Acoust Soc Am 72:1879-1890

Halpern BS, Walbridge $S$ et al (2008) A global map of human impact on marine ecosystems. Science 319:948-952

Hammerstad E (2000) EM technical note: backscattering and seabed image reflectivity $1-5$

Hartigan JA, Wong MA (1979) A K-means clustering algorithm. Appl Stat 28:100-108

Hewitt JE, Thrush SF, Halliday J, Duffy C (2005) The importance of small-scale habitat structure for maintaining beta diversity. Ecology $86: 1619-1626$

Hijmans RJ, van Etten J (2014) Raster: geographic data analysis and modelling. $\mathrm{R}$ package version $2: 15$. https://cran.r-project.org/ web/packages/raster/raster.pdf. Accessed Oct 2016

Holler P, Markert E, Bartholomä A, Capperucci R, Hass HC, Kröncke I, Reimers HC (2016) Tools to evaluate seafloor integrity: comparison of multi-device acoustic seafloor classifications for benthic macro fauna-driven patterns in the German Bight, southern North Sea. Geo-Mar Lett 37:93-109

Houziaux JS, Degrendele K, Norro A, Mallefet J, Kerckhof F, Roche M (2007) Gravel fields of the Western Belgian border, southern bight of the North Sea: a multidisciplinary approach to habitat characterization and mapping. 2nd International Conference Underwater Acoustic Measurements: Technologies and Results, 847-853. http://www.mumm.ac.be/Downloads/workshop_ artikel_jean_sebastien_houziaux.pdf. Accessed 9 Nov 2016

Houziaux JS, Fettweis M, Francken F, Van Lancker V (2011) Historic (1900) seafloor composition in the Belgian-Dutch part of the North Sea: a reconstruction based on calibrated visual sediment descriptions. Cont Shelf Res 31:1043-1056

Hughes-Clarke JE, Mayer LA, Wells DE (1996) Shallow-water imaging multibeam sonars: a new tool for investigating seafloor processes in the coastal zone and on the continental shelf. Mar Geophys Res 18:607-629

Hussain M, Chen D, Cheng A, Wei H, Stanley D (2013) Change detection from remotely sensed images: from pixel-based to object-based approaches. ISPRS J Photogramm Remote Sens 80:91-106

Ierodiaconou D, Laurenson L, Leblanc M, Stagnitti F, Duff G, Salzman S, Versace V (2005) The consequences of land use change on nutrient exports: a regional scale assessment in south-west Victoria, Australia. J Environ Manage 74:305-316

Jones JB (1992) Environmental impact of trawling on the seabed: a review. NZ J Mar Freshwat Res 26:59-67

Kenny AJ, Cato I, Desprez M, Fader G, Schüttenhelm RTE, Side J (2003) An overview of seabed-mapping technologies in the context of marine habitat classification. ICES J Mar Sci 60:411-418

Kursa MB, Rudnicki WR (2010) Feature selection with the Boruta package. J Stat Softw 36:1-13

Lecours V, Dolan MFJ, Micaleff A, Lucieer VL (2016) A review of marine geomorphometry, the quantitative study of the seafloor. Hydrol Earth Syst Sci 20:3207-3244

Li J, Tran M, Siwabessy J (2016) Selecting optimal Random Forest predictive models: a case study on predicting the spatial distribution of seabed hardness. PloS ONE 11:e0149089
Liaw A, Wiener M (2002) Classification and regression by Random Forest. R News 2:18-22

Lurton X (2010) An introduction to underwater acoustics-principles and applications, 2 edn. Springer, Berlin

Lurton X, Lamarche G (eds) (2015) Backscatter measurements by seafloor-mapping sonars. Guidelines and recommendations GeoHab Report. http://geohab.org/publications/

Luyten PJ, Jones JE, Proctor R (2003) A numerical study of the longand short-term temperature variability and thermal circulation in the North Sea. J Phys Oceanogr 33:37-56

Mathys M, Van Lancker V, De Backer A, Hostens K, Degrendele K, Roche M (2011) Application for a sand extraction concession in exploration Zone 4: baseline studies on the Hinderbanks and future impact monitoring. In: Study day: marine aggregate extraction: needs, guidelines and future prospects. FOD Economie, KMO, Middenstand en Energie, Bredene. http://www.vliz. be/imisdocs/publications/234541.pdf. Accessed 20 Nov 2016

Montereale-Gavazzi GOA, Madricardo F, Janowski L, Kruss A, Blondel P, Sigovini M, Foglini F (2016) Evaluation of seabed mapping methods for fine-scale classification of extremely shallow benthic habitats-application to the Venice Lagoon, Italy. Estuar Coast Shelf Sci 170:45-60

Pontius RG, Millones M (2011) Death to Kappa: birth of quantity disagreement and allocation disagreement for accuracy assessment. Int J Remote Sens 32:4407-4429

Pontius RG, Santacruz A (2014) Quantity, exchange and shift components of difference in a square contingency table. Int J Remote Sens 35:7543-7554

Pontius RG, Santacruz A (2015) diffeR: metrics of difference for comparing Pairs of maps. R package version 0.0-4. https:// CRAN.R-project.org/package=diffeR. Accessed 10 Nov 2016

Pontius RG, Shusas E, McEachern M (2004) Detecting important categorical land changes while accounting for persistence. Agric Ecosyst Environ 101:251-268

R Development Core Team (2008) R: a language and environment for statistical computing. R Foundation for Statistical Computing, Vienna. ISBN 3-900051-07-0. http://www.R-project.org. Accessed 18 Nov 2016

Rattray A, Ierodiaconou D, Monk J, Versace VL, Laurenson LJB (2013) Detecting patterns of change in benthic habitats by acoustic remote sensing. Mar Ecol Prog Ser 477:1-13

Roche M (2002) Utilisation du sonar multifaisceaux pour la classification acoustique des sédiments et son application à la cartographie de la zone de concession 2 de la mer territoriale et du Plateau Continental Belge: etude de faisabilité. Ministère des Affaires Économiques, Administration Qualité et Sécurité, Brussel. 1-67. http://www.vliz.be/en/imis?module=ref\&refid=60184. Accessed 9 Sept 2016

Roche M, Le Bas TP, Lurton X, Degrendele K, De Mol L, Van Lancker V, Baeye M, De Bisschop J, Vrigneaud C, Papili S, Lopera O, Augustin JM, Le Bouffant N, Berger L (2016) Backscatter patch test-inter-comparison of systems using shared reference areas for testing, calibration, and quality assessment. Geological and Biological Marine Habitat Mapping Conference, 15th International Symposium, Salvador Bahia, Brazil. http://www.geohab2016.org/sites/geohab16/files/documents/pdf/GeoHab\%20 abstract\%20booklet.pdf. Accessed 10 Nov 2016

Singh A (1989) Review article digital change detection techniques using remotely-sensed data. Int J Remote Sens 10:989-1003

Spearman J (2015) A review of the physical impacts of sediment dispersion from aggregate dredging. Mar Pollut Bull 94:260-277

Thrush SF, Dayton PK (2002) Disturbance to marine benthic habitats by trawling and dredging: implications for marine biodiversity. Annu Rev Ecol Syst 33:449-473

Van Lancker V (2017) Bedforms as Benthic Habitats: living on the edge, chaos, order and complexity. In: Guillén J, Acosta J, 
Chiocci FL, Palanques A (eds) Atlas of bedforms in the Western Mediterranean. Springer, Switzerland, pp 195-198

Van Lancker V, Baeye M (2015) Wave glider monitoring of sediment transport and dredge plumes in a shallow marine sandbank environment. PloS ONE 10:e0128948

Van Lancker V, Bonne W, Garel E, Degrendele K, Roche M, Van de Eynde D, Bellec V, Briere C, Collins MB, Velegrakis AF (2010) Recommendation for the sustainable exploitation of tidal sandbanks. J Coastal Res 51:151-164

Van Lancker V, Moerkerke G, Du Four I, Verfaillie E, Rabaut M, Degraer S (2012) Fine-scale geomorphological mapping of sandbank environments for the prediction of macrobenthic occurrences, Belgian Part of the North Sea. In: Harris P, Baker E (eds) Seafloor Geomorphology as Benthic Habitat: GeoHab Atlas of seafloor geomorphic features and benthic habitats. Elsevier, Oxford, pp 251-260

van Denderen PD, Bolam SG, Hiddink JG, Jennings S, Kenny A, Rijnsdorp AD, Van Kooten T (2015) Similar effects of bottom trawling and natural disturbance on composition and function of benthic communities across habitats. Mar Ecol Prog Ser 541:31-43

van Leeuwen S, Tett P, Mills D, van der Molen J (2015) Stratified and nonstratified areas in the North Sea: long-term variability and biological and policy implications. J Geophys Res 120:4670-4686

Van Lancker V, Baeye M, Montereale Gavazzi G, Van den Eynde D (2016) Monitoring of the impact of the extraction of marine aggregates, in casu sand, in the zone of the Hinder Banks. Period 1/1-31/12 2015 and synthesis of results 2011-2015. Brussels, RBINS-OD Nature. Report MOZ4-ZAGRI/I/VVL/2016/EN/ SR01. http://www.vliz.be/imisdocs/publications/268906.pdf. Accessed 18 Nov 2016

Verfaillie E, Van Lancker V, Van Meirvenne M (2006) Multivariate geostatistics for the predictive modelling of the surficial sand distribution in shelf seas. Cont Shelf Res 26:2454-2468

Watling L, Norse EA (1998) Disturbance of the seabed by mobile fishing gear: a comparison to forest clearcutting. Conserv Biol 12:1180-1197

Wells DE, Monahan D (2002) IHO S44 standards for hydrographic surveys and the variety of requirements for bathymetric data. Hydrogr J 104:9-16

Zvoleff A (2015) glcm: Calculate textures from grey-level co-occurrence matrices GLCMs in R. R package version 1.0. https:// cran.r-project.org/web/packages/glcm/glcm.pdf. Accessed Oct 2016 